\title{
Stromal Hedgehog pathway activation by IHH suppresses lung adenocarcinoma growth and metastasis by limiting reactive oxygen species
}

4

Sahba Kasiri, ${ }^{1,{ }^{*}}$ Baozhi Chen, ${ }^{1,{ }^{*}}$ Alexandra N. Wilson, ${ }^{1}$ Annika Reczek, ${ }^{1}$ Simbarashe Mazambani, ${ }^{2}$ Jashkaran Gadhvi, ${ }^{2}$ Evan Noel, ${ }^{1}$ Ummay Marriam, ${ }^{1}$ Barbara Mino, ${ }^{3}$ Wei Lu, ${ }^{3}$ Luc Girard, ${ }^{1}$ Luisa M. Solis, ${ }^{3}$ Katherine Luby-Phelps, ${ }^{4}$ Justin Bishop, ${ }^{5}$ Jung-Whan Kim, ${ }^{1}$ and James $\mathrm{Kim}^{1,6}$

\section{Affiliation of Authors:}

${ }^{1}$ Nancy B. and Jake L. Hamon Center for Therapeutic Oncology Research and Harold C. Simmons Comprehensive Cancer Center,

${ }^{2}$ Department of Biological Sciences, The University of Texas at Dallas, Richardson, Texas 75080

${ }^{3}$ Department of Translational Molecular Pathology, The University of Texas MD Anderson Cancer Center, Houston, TX 77030

${ }^{4}$ Department of Cell Biology,

${ }^{5}$ Department of Pathology, and

${ }^{6}$ Department of Internal Medicine, University of Texas Southwestern Medical Center, Dallas, TX 75390

Running Title: $\mathrm{IHH}$ suppresses lung adenocarcinoma by reducing ROS

* Authors contributed equally to this work.

To whom correspondence should be addressed:

James Kim, M.D., Ph.D.

6000 Harry Hines Blvd

Hamon Center for Therapeutic Oncology Research

UT Southwestern Medical Center

Dallas, TX 75390-8593

$\mathrm{Ph}: 214-648-4180$

Fax: 214-648-4940

james.kim@utsouthwestern.edu

Competing Interests: The authors declare no competing financial interests in relation to the work described. 


\section{Abstract}

Activation of the Hedgehog $(\mathrm{Hh})$ signaling pathway by mutations within its components drives the growth of several cancers. However, the role of Hh pathway activation in lung cancers has been controversial. We demonstrate that the Hh signaling pathway is activated in lung stroma in a paracrine manner. Genetic deletion of Shh in autochthonous murine lung adenocarcinoma had no effect on survival. Early abrogation of the pathway by an anti-SHH/lHH antibody $5 \mathrm{E} 1$ led to significantly worse survival with increased tumor and metastatic burden. Loss of IHH by in vivo CRISPR led to more aggressive tumor growth suggesting that $\mathrm{IHH}$, not $\mathrm{SHH}$, activates the pathway in stroma to drive its tumor suppressive effects - a novel role for $\mathrm{IHH}$ in the lung. Tumors from mice treated with $5 \mathrm{E} 1$ had decreased blood vessel density and increased reactive oxygen species (ROS). Treatment of KP mice with 5E1 and N-acetylcysteine, as a ROS scavenger, decreased tumor ROS levels, inhibited tumor growth and prolonged mouse survival suggesting that increased ROS levels from stromal Hh pathway inhibition spurred lung tumor growth. Thus, $\mathrm{IHH}$ induces stromal $\mathrm{Hh}$ pathway activation to suppress tumor growth and metastases, in part, by limiting ROS production. 
57 Lung cancer is the leading cause of cancer-related mortality in the U.S. and the world

\section{Introduction} (1) with 5-year survival of less than $5 \%$ for patients with metastatic disease (2). Nonsmall cell lung cancer (NSCLC) accounts for $\sim 85 \%$ of lung cancers, of which, adenocarcinoma is the most common subtype of NSCLC (3). KRAS mutations are the most common oncogenic driver mutations and occur in $\sim 30 \%$ of lung adenocarcinoma (LAD) (4). Currently, there are no specific targeted therapies available for mutant KRAS LAD.

The Hedgehog (Hh) signaling pathway is critical for embryonic development, tissue homeostasis and cancer (5). The pathway primarily operates in a paracrine manner in which a secreted $\mathrm{Hh}$ ligand $(\mathrm{SHH}, \mathrm{IHH}$, and $\mathrm{DHH}$ in mammals) binds to $\mathrm{PTCH}$, a twelve-pass transmembrane protein, to relieve its basal inhibition of SMO, a seven-pass transmembrane protein. SMO activation leads to activation and nuclear localization of the GLI2 transcription factor to initiate the transcription of target genes, including $P T C H$, GLI1, and HHIP (5).

Aberrant activation of the Hh signaling pathway by mutations in pathway components such as PTCH (6-11), SUFU (11-13), SMO (14-18), and amplifications of GLI1 and GLI2 $(19,20)$ drive tumor growth in basal cell carcinoma (BCC) $(6-8,17,21)$, medulloblastoma $(9,10,13,18-20,22,23)$, keratocystic odontogenic tumors $(24,25)$, meningioma $(12,14,16)$ and ameloblastoma (15). Vismodegib (26) and sonidgeib (27), two potent SMO antagonists, have been approved by the FDA for treatment of locally advanced and metastatic BCC $(28,29)$. Recently, glasdegib (30), another SMO antagonist, in combination with low dose cytarabine was recently approved by the FDA 
79 for acute myeloid leukemia patients 75 years or older or those with comorbidities that 80 preclude intensive chemotherapy (31).

81

82 Mutations of Hh pathway components are rare in sporadic epithelial tumors. It was

83 proposed that these cancers recapitulated development by secreting Hh ligands from

84 the tumor epithelia to activate the pathway in stromal cells that, in turn, secreted factors

85 instrumental for tumor initiation and growth (32-35). However, recent data in several

86 epithelial cancers suggest that paracrine activation of stroma by Hh ligands promotes

87 fibroblast expansion and restrains tumor growth early in the tumorigenic process.

88 Inhibition of stromal pathway activation led to accelerated tumor growth with more 89 aggressive, higher grade tumors (36-41).

91 In lung cancers, a variety of roles for the Hh signaling pathway has been reported. In

92 autochthonous mouse models of small cell lung cancer (SCLC), overexpression of $\mathrm{SHH}$

93 or SMOM2, a constitutively active mutant, in $R b^{-/} ; \operatorname{Trp}^{-/-}$cancer cells promoted tumor 94 proliferation $(42,43)$ and loss of SMO led to significantly decreased tumor formation 95 (42). Chemotherapy-resistant SCLC was more dependent on the pathway for growth 96 and treatment with sonidegib inhibited tumor growth of chemotherapy-resistant SCLC in 97 vivo (42). However, a phase III clinical trial showed no benefit of the addition of 98 vismodegib to standard chemotherapy in treatment-naïve SCLC patients (44). For 99 NSCLC, distinct modes of action have been reported for the Hh signaling pathway. In 100 lung squamous cell carcinoma (LSCC) tumor-spheres (45), SOX2 activation induced 101 upregulation of Hh acyltransferase (HHAT) (46), a critical component that palmitoylates 
102 Hh ligands $(47,48)$, and induces autocrine pathway activation to drive growth of LSCC 103 tumor-spheres but not bulk LSCC cells nor lung adenocarcinoma (LAD) tumor-spheres 104 (45). Alternatively, in PIK3CA-amplified LSCC, PI3K-mTOR pathway activation led to 105 non-canonical GLI1 expression independent of the Hh pathway (49). GLI1 activation 106 drove LSCC growth and treatment with combinatorial PI3K and GLI1 antagonists leads 107 to tumor regression in vivo (49). In LAD tumor-spheres and cell lines, paracrine $\mathrm{SHH}$ 108 from LAD epithelia activated the pathway in stroma to express VEGF that in turn, bound 109 to NRP2 receptor to activate the MAPK pathway and express GLI1 in a non-canonical 110 manner (50). Given these varied results of the pathway's role and modes of action in

111 lung cancers and other solid tumors, we tested the role of paracrine Hh pathway 112 activation in LAD tumorigenesis and growth in autochthonous mutant $\mathrm{Kras}^{\mathrm{G12D/+}} ; \operatorname{Trp53}^{\mathrm{fl} / f l}$ 113 mouse models of LAD.

115 Results

$116 \mathrm{SHH}$ ligand is expressed in lung adenocarcinoma and activates stromal Hh 117 pathway by a paracrine mechanism.

118 We evaluated the impact of SHH expression on lung adenocarcinoma (LAD) patients as $119 \mathrm{SHH}$ is the primary $\mathrm{Hh}$ ligand critical for lung development (51-54), adult lung airway 120 homeostasis $(55,56)$, and reported in lung cancers $(42,43,46,50,57)$. We assessed 121 the impact of high SHH mRNA expression in LAD patients in the Kaplan-Meier Plotter 122 (KM-Plotter; (58, 59)) database that aggregates Affymetrix microarray mRNA 123 expression with clinical annotation. From 720 LAD patients and using median 124 expression as the cutoff, a univariate Cox regression analysis of high SHH mRNA 
125 expression significantly correlated with worse overall survival $(P=0.0006$; Fig. 1 a) and 126 progression free survival $(P=0.044 ;$ Fig. 1c). These results were corroborated when

127 stage, gender and smoking history were accounted for in multivariate analyses for

128 overall survival (Fig. 1b) but not in progression-free survival (Fig. 1d). We then surveyed

12934 human LAD cell lines for Hh ligand expression by qPCR (Fig. 1e). Mutant KRAS cell

130 lines were sought as mutant KRAS has been reported to upregulate $\mathrm{SHH}$ expression

131 (60). The majority of high $\mathrm{Hh}$ ligand expressing cell lines, defined as $>4 \mathrm{x}$ expression of

132 normal bronchial epithelial HBEC7-kt cells, also expressed mutant KRAS (Fig. 1e). H23,

H2887, HCC44, H2558 LAD cells expressed high levels of SHH protein whereas H441

and H3122 expressed low levels of SHH protein as measured by immunoblot (Fig. 1f),

135 consistent with qPCR results (Fig. 1e).

137 To test whether SHH secreted from LAD cells were active, we co-cultured three cell 138 lines with the highest level of $\mathrm{SHH}$ (Fig. 1e, f) with Hh-pathway responsive Shh-Light2 139 mouse embryonic fibroblasts that contain an 8x-GLI binding site-firefly luciferase reporter (61). Treatment of Shh-Light2 cells alone with SHHN conditioned medium (CM) (62) induced high levels of Hh pathway activity that was suppressed by KAAD142 cyclopamine $200 \mathrm{nM}$ (63), a potent SMO antagonist, and 5E1 $10 \mu \mathrm{g} / \mathrm{ml}$, a blocking 143 monoclonal antibody that binds to $\mathrm{SHH}$ and $\mathrm{IHH}(64,65)$. Co-culture of high $\mathrm{SHH}-$ expressing cells (H2887, H23, and HCC44) with Shh-Light2 cells, but without addition of exogenous $\mathrm{SHH}$, resulted in potent activation of the pathway in Shh-Light2 cells, 146 compared to normal airway epithelial HBEC-7kt cells (Fig. 1g). Treatment of these co147 cultured cells with KAAD-cyclopamine and 5E1 inhibited Hh pathway activation in Shh- 
Light2 cells (Fig. 1g). In contrast, low SHH-expressing H3122 cells did not significantly induce Hh pathway activation in Shh-Light2 cells. These results, in particular those with $5 E 1$, suggested that $\mathrm{SHH}$ from LAD cells activate the pathway in stromal cells in a paracrine manner.

\section{SHH does not affect lung adenocarcinoma growth in vivo.}

We next sought to test the role of stromal Hh pathway in lung tumor development. As reliable anti-SHH antibodies for immunohistochemistry (IHC) were not commercially available, we tested for Shh mRNA expression by in situ hybridization. We validated Shh mRNA probes in the neural tube of E11.5 mouse embryos where $\mathrm{SHH}$ is highly expressed in the notochord $(66,67)$ and floor plate $(68,69)$ (Supplement Fig. 1). Ten weeks after infection of Kras $^{\text {Lox-Stop-Lox-G12D/+ }} ; \operatorname{Trp53^{f/fl}}(K P)$ mice $(70)$ with adenovirusexpressing cre recombinase (adeno-cre) by intranasal inhalation, LAD expressed Shh mRNA by in situ hybridization (Fig. 2a). We further verified the expression of Shh mRNA specifically $K P$ transformed lung epithelia. Lungs from uninfected $K P$ mice and $K P ;$ Rosa26 $^{\text {Lox-mtdTomato-Stop-Lox-mGFP/+ }}(K P m T m G)$ mice (71), a strain that conditionally switches from constitutive tdTomato expression to GFP expression and initiates LAD when exposed to cre recombinase (Supplement Fig. 2a), infected with adeno-cre were enzymatically dissociated into single cells. Lung epithelial cells were isolated using FACS - CD31- (endothelial cell antigen), CD45- (leukocyte antigen), EpCAM+ (epithelial cell antigen) for uninfected KP and EpCAM+, GFP+ (adeno-cre infected cells) for KPmTmG epithelia, respectively (Supplement Fig. 2) - and Shh mRNA measured by qPCR. Infected KPmTmG lung epithelia expressed higher levels of Shh mRNA than 
171 wild type lung epithelia of uninfected KP mice (Fig. 2b). We next tested the requirement

172 of stromal Hh pathway activity for LAD tumorigenesis by crossbreeding $K P$ with $S h h^{f / f l}$

173 (72) mice to generate $K P, K P ; S h h^{f l /}$, and $K P ; S h h^{f l / f l}$ strains to induce LAD with wild-type

174 (wt), heterozygous, and homozygous loss of $\mathrm{SHH}$ expression. Surprisingly, $K P$, $175 K P ; S h h^{f l /}$, and $K P ; S h h^{f / f l}$ mice did not show any differences in survival after LAD

176 induction with adeno-cre (Fig. 2c). To verify that Shh was indeed deleted in $K P ; S h h^{f / f l}$

177 mice, we isolated EpCAM+;GFP+ infected lung epithelial cells by FACS from KPmTmG

178 and KPmTmG;Shh ${ }^{f l / f l}$ mice 3 weeks after adeno-cre infection, analogous to Supplement

179 Fig. 2b, and tested for Shh mRNA expression by qPCR. Indeed, $K P ; S h h^{f l / f l}$ infected epithelial cells expressed Shh mRNA approximately 6 orders of magnitude less than $K P$

181 epithelial cells (Fig. 2d), suggesting that Shh was indeed knocked out. Furthermore, no 182 significant differences in tumor size were seen in the lungs of $K P, K P ; S h h^{f l /+}$, and $183 K P ; S h h^{f l / f l} 10$ weeks after infection (Fig. 2e, f). Taken together, these results suggest 184 that SHH may not play a role in mutant Kras LAD tumorigenesis and progression.

Activation of the Hh pathway in stroma prolongs survival by restraining tumor growth and metastasis in vivo.

188 To further examine the effect of paracrine Hh pathway activity in lung tumorigenesis, we 189 first identified 5E1 $10 \mathrm{mg} / \mathrm{kg}$ twice per week as an optimal dose through an in vivo Hh 190 pathway-dependent hair regrowth assay (Supplement Fig. 3) (73, 74). KP mice were 191 then treated with $5 \mathrm{E} 1$ or $\operatorname{lgG}_{1}$ control starting 2 or 6 weeks after tumor initiation by 192 adeno-cre infection (Fig. 3a) such that the pathway was inhibited early in the 193 tumorigenic process (2 weeks) or once adenomas with nuclear atypia had been 
194 195 196

197

198

199

200

201

202

203

204

205

206

207

208

209

210

211

212

213

214

215

216

established (6 weeks) (70). KP mice treated with $5 \mathrm{E} 1$ starting 2 weeks after tumor initiation had significantly worse survival (Fig. 3b) compared to $\lg _{1}$ treated control mice in contrast to mice treated with 5E1 starting 6 weeks after adeno-cre infection (Fig.3c). Furthermore, $K P$ mice treated with $5 \mathrm{E} 1$ at the 2 week time point exhibited significantly higher rates of metastases (Fig. 3d), primarily to mediastinal lymph nodes and pleura (Fig. 3 e, f). Examination of LAD tumors after 8 weeks of $5 E 1$ treatment (10 weeks after adeno-cre infection) demonstrated significantly larger tumor burden (Fig. $3 g-i)$ with a greater proportion of poorly-differentiated tumors and less well-differentiated tumors (Fig. 3j, k) compared to mice treated with $\lg _{1}$ control. Thus, pharmacologic inhibition of stromal Hh pathway induced greater tumor burden with greater metastases and worse survival, suggesting that stromal Hh pathway activity restrains LAD growth and metastasis.

\section{$\mathrm{IHH}$ is the predominant $\mathrm{Hh}$ ligand in murine mutant Kras LAD.}

With the disparate outcomes of genetic SHH loss (Fig. 2c, e, f) and pharmacologic blockade by $5 E 1$ (Fig. 3b, d - k), we hypothesized that IHH may play a role in LAD tumorigenesis as $5 \mathrm{E} 1$ binds both $\mathrm{SHH}$ and $\mathrm{IHH}$. We verified that $5 \mathrm{E} 1$ can inhibit stromal pathway activation by $\mathrm{IHH}$ using Shh-Light2 cells stimulated with either recombinant $\mathrm{IHH}(\mathrm{rlHH})$ or rSHH (Fig. 4a). Of note, there was almost no induction of pathway activity with recombinant $\mathrm{DHH}$ treatment (results are not shown). As reliable antibodies for $\mathrm{IHH}$ IHC and immunoblots were not commercially available, we turned to RNA in situ hybridization. KP LAD 10 weeks after adeno-cre infection expressed substantial amounts of Ihh mRNA (Fig. 4b). To further verify that IHH is expressed by transformed 
217 lung epithelial cells, EpCAM+,GFP+ epithelial cells were isolated by FACS (analogous

218 to Supplement Fig. 2b) from KPmTmG mice 6 weeks after adeno-cre infection. The

219 sorted epithelial cells show a striking increase in Ihh mRNA expression in comparison to

220 Shh mRNA as measured by qPCR (Fig. 4c). To genetically test the requirement of IHH

221 to suppress LAD tumorigenesis and growth, we used the pSECC lentiviral in vivo

222 CRISPR/Cas9 system (75) that encodes for Cre recombinase to initiate tumorigenesis,

223 Cas9 for gene editing, and sgRNA against the gene of interest. Several candidate

224 sgRNA against Ihh (sg/hh) were tested with SURVEYOR assay (Supplement Fig. 4)

225 and the sgRNA sequence (\#2, hereafter just sg/hh) with the greatest percentage of

226 digested bands was chosen for further study. We tested pSECC-Ihh for loss of Ihh

227 mRNA expression by qPCR in 808-T3 cells, a murine KP LAD cell line with high Ihh

228 mRNA expression (Supplement Fig. 5a). Approximately half of the clones from 808-T3

229 cell lines transfected with the pSECC-Ihh showed substantial decreases in Ihh mRNA

230 expression compared to pSECC-GFP control (Supplement Fig. 5b). Subsequently,

$231 K P ;$ Rosa26 $^{L S L-f L u c /+}(K P L)$ mice were infected with lentiviral particles containing pSECC-

232 Ihh or pSECC-GFP via intratracheal administration and tumor growth monitored by

233 bioluminescence imaging (BLI). Infection with pSECC-Ihh induced significant tumor

234 growth compared to pSECC-GFP control 18 weeks after infection (Fig. 4, d-f). KPL mice

235 infected with pSECC-GFP eventually developed tumors that were detected by BLI at

236 22-26 weeks after infection (Fig. 4d).

\section{IHH in human lung adenocarcinoma.}

238 We next tested for IHH mRNA by in situ hybridization in human LAD samples in mutant 239 and wild type KRAS and TP53 samples. Two of the three mutant KRAS;TP53 samples 
240

241

242

243

244

245

246

247

248

249

250

251

252

253

254

255

256

257

258

259

260

261

262

expressed $I H H$ mRNA in malignant cells whereas only one of the six wild type samples expressed $I H H$ mRNA (Fig. 5a, Supplement Fig. 6). All of the $I H H$ mRNA positive tumors had a predominance of lepidic histology with mucinous features (Supplement Fig. 6). Lepidic histology has been correlated with less aggressive biology. The prognosis of mucinous histology in LAD is uncertain currently (76). Re-examination of the 34 human LAD cell lines (Fig. 1e) revealed only 4 lines with IHH mRNA significantly elevated beyond the normal lung epithelial line HBEC-7kt (Fig. 5b). As most of the cell lines were generated from patients with late stage or metastatic adenocarcinomas, the dearth of cancer lines with upregulated $I H H$ mRNA corroborates the in situ results of IHH mRNA in more indolent lepidic histologies (Fig. 5a, Supplement Fig. 6). Univariate Cox regression analysis of a clinically annotated microarray database of human LAD (KM Plotter; (58)) revealed that patients with high expression of Ihh mRNA had better overall $(P=0.0001 ;$ Fig. $5 c)$ and progression free $(P=0.0069 ;$ Fig $5 e)$ survival compared to those with low expression. These results remain consistent after

multivariate analyses when stage, gender, and smoking history are considered (Fig. 5d, f), in agreement with our murine LAD data (Fig. 3b and 4, d-f). The data here suggest that $\mathrm{IHH}$ is sufficient to suppress tumor initiation and growth and that $\mathrm{SHH}$ is dispensable for LAD tumorigenesis.

\section{Loss of Stromal Hh pathway inhibits angiogenesis and increases reactive oxygen} species.

61 The Hh signaling pathway has been implicated in the regulation of angiogenesis in normal tissues $(77,78)$ and cancer $(79,80)$ through induction of angiogenic factors 
263 including VEGFs and ANG1, 2. Examination of CD31 expression, a marker of

264 endothelial cells, showed decreased blood vessel density in LAD tumors treated with

265 anti-SHH/IHH 5E1 antibody compared to $\operatorname{lgG}_{1}$ treated tumors (Fig. 6a, b). As the effects

266 of stromal Hh pathway inhibition were seen with mice when treatment was initiated 2

267 weeks after adeno-cre infection (Fig. 3b, d-k), we hypothesized that the inability of

268 growing tumors to generate new vessels would lead to early hypoxia and production of

269 reactive oxygen species $(81,82)$, that in turn, would promote tumor proliferation and

270 growth (83-85). We developed 2 macros (ROI_Draw and Nuclear_Fraction_Calculator)

271 for ImageJ (86) or Fiji (87) to quantify DAB stained nuclei of phospho-histone

$2722 \mathrm{AX}(\gamma \mathrm{H} 2 \mathrm{AX})$, a protein that responds to double stranded DNA breaks and a marker of

273 oxidative stress $(88,89)$. Nuclear_Fraction_Calculator counts DAB stained nuclei and

274 total nuclei in digital images of tissue sections and calculates the fraction of IHC positive

275 nuclei within regions of interest (ROI; tumors in our studies) that have been drawn

276 interactively with ROI_Draw. With these macros, LAD from mice treated with 5E1

277 showed significantly higher fraction of nuclei stained with $\gamma \mathrm{H} 2 \mathrm{AX}$ than tumors from $\lg _{1}$

278 treated mice (Fig 6c, d), suggesting increased DNA damage from reactive oxygen

279 species (ROS). To assess whether ROS from stromal Hh pathway inhibition induced

280 accelerated tumor growth, $K P$ mice were treated with $5 E 1$ and $N$-acetyl cysteine (NAC),

281 as a scavenger of ROS and precursor to the antioxidant, glutathione (GSH) (Fig. 6e).

282 Treatment with NAC and 5E1 prolonged surv

283 ival compared to 5E1 and vehicle control (Fig. 6f) whereas treatment with NAC and IgG 1

284 did not affect survival (Fig. 6g). Furthermore, the median survival of 5E1 with NAC

285 approximated that of $\lg _{1}$ with vehicle control (Supplement Fig. 7). Interestingly, the 
286 rate of metastases did not decrease when mice were treated with $5 \mathrm{E} 1$ and NAC 287 compared to 5E1 and vehicle control (Fig. 6h). However, the tumor burden of mice 288 treated with 5E1 and NAC decreased substantially compared to mice treated with $5 \mathrm{E} 1$ 289 and vehicle control 10 weeks after adeno-cre infection (Fig. 6i, j) and corresponded to 290 decreased ROS as measured by $\gamma \mathrm{H} 2 \mathrm{AX}$ stained nuclei (Fig. 6k, I). These data suggest 291 that $\mathrm{IHH}$ restrains tumor growth through support of angiogenesis with limiting ROS 292 production early in the tumorigenic process.

\section{Discussion}

295 We have shown that mutant KRAS LAD secretes Hh ligands to activate stromal cells in a paracrine manner (Fig. 1g), that $\mathrm{IHH}$ (Fig. 3), rather than $\mathrm{SHH}$, is the dominant ligand 297 in early transformed lung airway cells and that it restrains tumor growth (Fig. 3g-i, 4d-f), 298 grade (Fig. 3j, k) and metastases (Fig. 3d-f). Inhibition of stromal Hh pathway activation by $\mathrm{IHH}$ decreased angiogenesis (Fig. 6a, b) and significantly increased ROS (Fig 6c, d)

In accordance with previous studies (36-40, 90), paracrine Hh activation of stroma, 303 particularly early in the tumorigenic process, suppresses lung tumor growth, formation of aggressive histologies and metastases. A surprising result of our studies was the central role of $\mathrm{IHH}$, instead of $\mathrm{SHH}$, to suppress tumor growth. $\mathrm{SHH}$ is the dominant ligand that regulates lung development $(51-54,91)$, adult lung airway homeostasis (55,

$30756,92)$, and lung cancers $(42,43,46,50,57) . \mathrm{IHH}$ is expressed in the adult colon (93) 
However, to our knowledge, $\mathrm{IHH}$ activity has not been reported in the lung. Further studies are needed to test if $\mathrm{IHH}$ has a role in the homeostasis of the adult lung epithelia or if it is unique to lung cancers.

In our studies, loss of stromal pathway activation in KP LAD decreased blood vessel density (Fig. 6a, b) suggesting that the Hh signaling pathway induces angiogenesis in the lungs consistent with reports in other organs $(77,78,95)$. However, loss of stromal Hh pathway activation in KP pancreas ductal adenocarcinoma (PDAC) had the opposite effect and led to increased tumor blood vessel density $(35,36)$. Inhibition of angiogenesis through VEGFR2 antagonism in $K P ; S h h^{f / f t}$ PDACs prolonged mouse survival (36). Another study reported that loss of Hh ligand co-receptors, GAS1 and $\mathrm{BOC}$, in mouse embryonic and pancreas cancer-associated fibroblasts (CAFs) led to partial suppression of pathway response to $\mathrm{SHH}$ and increased angiogenesis (96). Loss of co-receptors GAS1, BOC, and CDO in fibroblasts caused a more severe suppression of the pathway and inhibited angiogenesis through modulation of angiogenic ligands VEGFA, ANGPT1, 2 (96). If stromal cells respond distinctly to $\mathrm{SHH}$ and $\mathrm{IHH}$ ligands, then $\mathrm{IHH}$ may play a more prominent role in angiogenesis in LAD than SHH due to the lower potency of IHH (Fig. 4a) analogous to the diminished pathway response of Gas $1^{-/-}$ ;Boc ${ }^{-/}$fibroblasts in pancreatic cancer (96). Previous studies also have noted the differences in genomic and transcriptomic heterogeneity (97) and effectors downstream of mutant Kras (98) between murine KP LADs and PDACs. Such differences may also play a role in the tumor microenvironment where responses to Hh ligands may differ significantly between pancreas and lung stroma. The distinct phenotypic outcomes of 
332 stromal Hh pathway activation in LAD and PDAC suggest that tumor-stromal

333 interactions of various cancer types will need to be studied individually and cautions

334 against broad generalizations.

ROS exhibit seemingly paradoxical effects of tumor growth enhancement and tumor

337 cytotoxicity depending on their levels (99). Oncoproteins, such as mutant KRAS and 338 MYC, and hypoxic states can increase cellular ROS levels $(85,100)$ that enhances 339 tumor growth $(85,101-103)$. But high levels of ROS can be cytotoxic and cancer cells upregulate antioxidant proteins including glutathione peroxidases, peroxiredoxins, and NRF2 to maintain ROS at optimal levels (100). Here, we have shown that loss of stromal pathway activity early in the tumorigenic process increased ROS in tumor cells

344 prolonged survival with retardation of tumor growth in $K P$ LAD (Fig. 6f, i-I). Our results suggest that KP LAD can tolerate higher levels of ROS to accelerate tumor growth. Further studies will be needed to identify the upper limit of tolerable ROS levels before cytotoxic effects become dominant.

Our studies here highlight the tumor suppressive roles of stromal Hh pathway activation by $\mathrm{IHH}$ via limiting hypoxia and ROS generation through angiogenesis and reinforce the 351 anti-oncogenic role of stroma early in the tumorigenic process. Identification of factors 352 that negatively regulate $\mathrm{IHH}$ production in LAD may serve as targets of small molecule 353 or antibody therapeutics to enhance $\mathrm{IHH}$ expression and restrain tumor growth and 354 metastases. Such therapeutic strategies may be employed in in early stage or locally 
355 advanced disease prior to surgery/high dose radiation or concurrent chemoradiation,

356 respectively, where treatment failure often occurs due to distant metastases. Also,

357 identification of such factors may serve as biomarkers to determine the early stage

358 patients that might benefit from more aggressive therapy.

359

360 Materials And Methods

361 Cell culture

362 All human lung adenocarcinoma cell lines were obtained from the Hamon Cancer

363 Center Collection (UT Southwestern Medical Center, UTSW), were DNA fingerprinted

364 with a PowerPlex 1.2 kit (Promega) and tested for mycoplasma using e-Myco kit (Boca

365 Scientific). The cell lines were generated between 1979 and 2007. Cells were

366 maintained in RPMI-1640 (Life Technologies) with 5\% fetal bovine serum (FBS). 808-T3

367 and Green-Go (75) cell lines were kind gifts from Dr. David McFadden (UTSW) and Dr.

368 Tyler Jacks (MIT), respectively, and were maintained in DMEM (Life Technologies) with

$36910 \%$ FBS. All cells were maintained at $37^{\circ} \mathrm{C}$, with $5 \% \mathrm{CO} 2$, and under humidified

370 conditions.

371

372 Drugs and reagents

$3735 E 1$ antibody was generated in our laboratory (see supplemental material and methods)

374 and prepared in PBS. IgG 1 (InVivoMab, BE0083) was diluted in PBS. KAAD-

375 cyclopamine (Millipore) was prepared in DMSO. Recombinant SHH (C25II) (R\&D

376 Systems) and $\mathrm{IHH}$ (C28II) (Genscript) were prepared in PBS containing 0.1\% bovine

377 serum albumin (BSA). N-Acetyl-L-cysteine (NAC) was purchased from Sigma-Aldrich 
378 and prepared in PBS for i.p. injection or sterile tap water for supplemented drinking

379 water. For NAC solution, $\mathrm{pH}$ was adjusted to 7.4 .

\section{GLI-reporter assay}

382 Shh-Light2 cells (61), a clonal NIH-3T3 cell line that stably expresses 8xGLI-binding 383 site-firefly and TK-Renilla luciferase reporters, were co-cultured with LAD cell lines in 384 24-well plates until confluent and then treated with KAAD-cyclopamine (Millipore) $385200 \mathrm{nM}, 5 \mathrm{E} 1$ antibody $10 \mu \mathrm{g} / \mathrm{ml}$ or recombinant SHHN protein $1 \mu \mathrm{g} / \mathrm{ml}$ in DMEM 386 containing $0.5 \%$ ( $\mathrm{vol} / \mathrm{vol})$ bovine calf serum. Luciferase activity was measured by 387 Fluostar Optima (BMG Labtech) using Dual Luciferase Assay Reporter System 388 (Promega).

\section{Quantitative real-time PCR}

391 Total RNA was extracted using TriZol (Invitrogen) and then purified with PureLink RNA 392 Mini Kit (Invitrogen). cDNA was generated using iScript cDNA synthesis kit (Bio-Rad) or 393 Superscript III First Strand Synthesis System (Invitrogen). qPCR was performed using 394 Bio-Rad CFX real-time cycler and SYBR Green Master Mix (Bio-Rad). Data are 395 presented as fold change relative to control samples using the $\Delta \Delta \mathrm{Ct}\left(2^{-\Delta \Delta \mathrm{Ct}}\right)$ method 396 with HPRT1 or GAPDH as an internal control gene. Primers for qPCR are listed in 397 Supplementary Table 1. 
400 Cell lysates were generated and analyzed as previously described (104). Briefly, cells

401 were lysed in ice-cold lysis buffer (M-PER Mammalian Protein Extraction Reagent

402 (Thermo Scientific) with protease inhibitors (Roche) and PhosSTOP phosphatase

403 inhibitors (Roche). Cell lysates were centrifuged at $14,000 \mathrm{rpm}$ for $5 \mathrm{~min}$ at $4^{\circ} \mathrm{C}$ and

404 then supernatants were collected. Protein concentration was measured using BCA

405 protein assay kit (Pierce) following the manufacturer's instructions. The following

406 primary antibodies were used: SHHN (1:1000, Cell Signaling Technology, C9C5) and

$407 \operatorname{HSP90}$ (1:2000, Santa Cruz biotechnology, sc-13119).

408

409

sg-RNA design and cloning

410 All sg-RNA against Ihh were designed using GE Dharmacon web tool. The sg-RNA

411 sequences targeting GFP was published previously (105). sg-RNA oligo candidates

412 (listed on supplementary table 2) were inserted into pSECC vector (a kind gift from Dr.

413 Tyler Jacks, Addgene, 60820) by following the protocol available at this website:

414 http://genome-engineering.org/gecko/.

415

416 Co-transfection of 808-T3 cells

417 Cells were grown to $70 \%$ confluency on 6 well plates and then co transfected with

418 pCMV:DsRed(FRT)GFP plasmid expressing DsRed (Addgene, 31128) and pSECC-Ihh

419 or pSECC-GFP using Lipofectamine 3000 (Thermo Fisher Scientific) following

420 manufacturer instructions. DsRed+ transfected cells were FACS sorted and plated at

421 limiting dilutions to isolate clonal lines. 


\section{Animals}

424 All animal related experiments and procedures were performed with prior approval of

425 the Institutional Animal Care and Use Committee at UTSW. FVB, Kras ${ }^{\text {Lox-Stop-Lox-G12D/+ }}{ }^{\text {, }}$

$426 \operatorname{Trp53}^{f / f l}, S h h^{f / / f l}$ and, Rosa26 $6^{\text {Lox-mtdTomato-Stop-Lox-mGFP/+ }}$ mice were purchased from

427 Jackson Laboratory (Bar Harbor, ME) and compound strains were generated through

428 cross-breeding.

429

\section{Infection and Treatment of Mice}

431 Adenovirus-expressing cre recombinase (Ad5-CMV-Cre) was purchased from Vector

432 Development Laboratory (Baylor College of Medicine, Houston). Six to ten weeks old 433 mice were infected by intranasal instillation with $3 \times 10^{8}$ pfu per mouse as described 434 previously (106) to initiate lung tumorigenesis. For the in vivo CRISPR experiments, 10

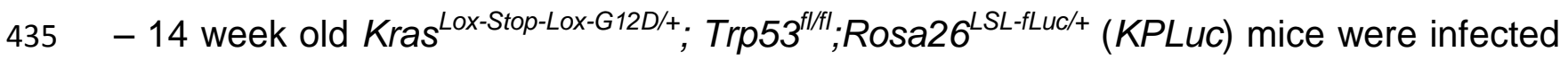
436 with $5 \times 10^{4}$ ifu of lentivirus containing pSECC-Ihh or pSECC-GFP via intratracheal 437 administration as described previously (106). KP or KP;Rosa26 $6^{\text {Lox-mtdTomato-Stop-Lox-mGFP/+ }}$ 438 (KPmTmG) mice were treated with $5 \mathrm{E} 1$ or $\lg _{1}, 10 \mathrm{mg} / \mathrm{kg}$ intraperitoneally (i.p.) twice 439 per week starting 2 or 6 weeks after adeno-cre infection. For NAC study, KP mice were 440 infected with adeno-cre then treated with NAC $200 \mathrm{mg} / \mathrm{kg}$ i.p. on days 12 and 13 after 441 adeno-cre infection. Afterwards, NAC $1 \mathrm{~g} / \mathrm{L}(\mathrm{pH}=7.4)$ was provided in the drinking water. 442 Supplemented drinking water was changed every 2-3 days for the duration of study. 
445 Mice were anesthetized with Avertin 25 mg/kg i.p., lungs perfused with ice-cold PBS, 446 inflated with ice-cold 4\% Paraformaldehyde (PFA) in PBS by intra-tracheal instillation,

447 then fixed in $4 \%$ PFA at $4^{\circ} \mathrm{C}$ for 24 hours. Tissue processing and paraffin embedding 448 were performed by Tissue Management Core Facility or Histo-Pathology Core Facility at 449 UTSW. Frozen lung tissue blocks were made by inflating lungs with 50\% (v/v) OCT 450 (Tissue-Tek) in PBS and embedded in cryomold with 100\% OCT on dry ice, and stored 451 in $-80^{\circ} \mathrm{C}$. Five and fifteen micron thick sections were made from each PFA fixed 452 paraffin-embedded and frozen tissue blocks respectively and subjected to hematoxylin 453 and eosin (H\&E) or immunohistochemistry staining. Brightfield images were taken using

454 a Nikon Eclipse E800 or Hamamatsu Nanozoomer in Whole Brain Microscopy Facility 455 (UTSW). Tumor area on H\&E stained images were measured using NIS Elements 456 imaging software (Nikon). The fraction of $\mathrm{IHC}$ positive nuclei in each tumor was 457 estimated using ImageJ or Fiji as described in supplemental material and methods.

459 Immunohistochemistry

460 Heat-mediated antigen retrieval (citrate buffer, $\mathrm{pH}$ 6) was used for tissue sections from 461 paraffin-embedded blocks. Goat serum (Sigma) or donkey serum (Sigma) was used to 462 block for 1 hour, and diluted primary antibodies were applied at $4^{\circ} \mathrm{C}$ overnight. 463 Vectastain ABC (Vector Labs) with DAB substrate (Vector Labs) was used to optimize 464 staining according to the manufacture's protocol. The following primary antibodies were 465 used: Ser139-p-Histone H2A.X (1:1,000; Cell Signaling Technology, 9718) and 466 CD31(1:500, Cell Signaling Technology, 77699). 


\section{RNA in situ hybridization method (RNAScope)}

Murine Samples. Five micrometer sections from paraffin embedded lungs were deparaffinaized, fixed in $10 \%$ formalin solution at room temperature for 24 hours and

471 then subjected to RNAscope assay using RNAscope 2.0 HD Reagent Kit-Red 472 (Advanced Cell Diagnostics (ACD), 310034) and following manufacturer instructions. 473 Mm-Ihh-noXHs (413091) and Mm-Shh (314361) probes were used for murine Ihh and 474 Shh mRNA detection, respectively. Dapb (negative control, 310043, ACD) and PPIB 475 (positive control, 313911, ACD) were used for quality control (data not shown). Human 476 Samples. Please see Supplementary Methods for full details. Briefly, in situ 477 hydbridization was performed on an automated Leica Bond RX autostainer (Leica 478 Biosystems, Nussloch, GmbH). LS 2.5 Probe- Hs-IHH probe (472388, ACD) was used. 479 RNA expression of IHH was scored using a semi-quantitative scoring system as follows: 480 0: no staining or <1 dot/10 cells; $1+: 1-3$ dots/cell; $2+: 4-9$ dots per cell, None or very few 481 dot clusters; $3+$ : 10-15 dots/ cell and <10\% dots are in clusters; $4+:>15$ dots/cell and $482>10 \%$ dots are in clusters. Positive (PPIB, Hs-PPIB, 313908) and negative (Dapb, Hs483 PPIB, 312038) control probes were also evaluated, dapB score of $<1$ and PPIB score $484 \geq 2$ with relatively uniform PPIB signals throughout the sample were considered 485 adequate for analysis (data not shown).

487 Histology Analysis

$488 \mathrm{H} \& \mathrm{E}$ stained lungs with tumors from $K P$ mice were examined. The pathologist was 489 blinded to the conditions of the experiment. As nearly all tumors $<0.5 \mathrm{~mm}$ were well- 
490 differentiated histology, only tumors $\geq 0.5 \mathrm{~mm}$ were examined. Tumors were graded as

491 poor, moderate or well differentiated cancers.

492

493 Digestion of lung tissue and FACS-sort of lung epithelial cells

494 Single cell suspensions of whole lungs were prepared as described previously (107).

495 For FACS, single cell suspensions were incubated with eBiosccience Fixable Viability

496 Dye eFluoor ${ }^{\mathrm{TM}} 780$ (Invitrogen) and the following antibodies (0.6 $\mu \mathrm{g}$ per $10^{7}$ cells):

497 PerCP-Cy5.5 Rat Anti-Mouse CD45 (BD Pharmingen, 550994), PE-Cy7 Rat Anti-Mouse

498 CD31 (BD Pharmingen, 561410), and Brilliant Violet 421 anti-mouse CD326 (Ep-CAM)

499 (BioLegend, 118225) on ice for 45 minutes, and then subjected to FACS-sorting using

500 FACS Aria II (BD Biosciences) at the Moody Foundation Flow Cytometry Core Facility

501 at the Children's Research Institute at UTSW. Flow cytometry data were analyzed with

502 FlowJo v10.

503

504 Statistical analysis

505 GraphPad Prism 7 software was used to generate the graphs and for statistical 506 analysis. Unpaired, two-sided Student's $t$-test was used for comparison of 2 groups.

507 Mantel-Cox log-rank test was used for statistical significance of murine surivival curves.

508 Univariate Cox regression analysis was performed to calculate hazard ratio and log509 rank $\mathrm{P}$ values per KM-Plotter (58) (http://kmplot.com/analysis/) for the human LAD 510 Kaplan-Meier curves. 


\section{Acknowledgement}

514 We thank Dr. John D. Minna for valuable discussions, Drs. Rolf Brekken and David

515 Wang for their helpful comments on the manuscript, Nicolas Loof, Kim Nguyen, and

516 Terry Shih for assistance with FACS, and Denise Ramirez of the Whole Brain

517 Microscopy Facility. We also thank John Shelton at UTSW HistoPathology Core and Dr.

518 Cheryl Lewis at UTSW Tissue Management Core for assistance with tissue processing

519 and embedding. This work was supported in part by the National Cancer Institute

520 (P50CA70907, R01CA196851: J.K.; R21 CA208746: J.-W. K.), National Heart, Lung,

521 and Blood Institute (5T32HL098040 to S.K.), American Cancer Society (RSG-16-090-

522 01-TBG: J.K.), American Lung Association (LCD-400239: J.-W.K.), Sidney Kimmel

523 Foundation for Cancer Research (SKF-14-057: J.K.), Lung Cancer Research

524 Foundation (J.K.) and Bonnie J. Addario Lung Cancer Foundation (J.K.).

525

\section{Competing Interests}

527 The authors declare no competing financial interests in relation to the work described. 
1. Siegel RL, Miller KD, Jemal A. Cancer statistics, 2016. CA Cancer J Clin. 2016;66(1):7-30.

2. National Cancer Institute Surveillance E, and End Results Program. Cancer Stat Facts: Lung and Bronchus Cancer [Available from: https://seer.cancer.gov/statfacts/html/lungb.html.

3. http://seer.cancer.gov/csr/1975 2007/results merged/sect 15 lung bronchus.pdf.

5364 4. Cancer Genome Atlas Research N. Comprehensive molecular profiling of lung 537 adenocarcinoma. Nature. 2014;511(7511):543-50.

$538 \quad 5 . \quad$ Varjosalo M, Taipale J. Hedgehog: functions and mechanisms. Genes Dev. 539 2008;22(18):2454-72.

540 6. Gailani MR, Stahle-Backdahl M, Leffell DJ, Glynn M, Zaphiropoulos PG, 541 Pressman C, et al. The role of the human homologue of Drosophila patched in sporadic 542 basal cell carcinomas. Nat Genet. 1996;14(1):78-81.

543 7. Hahn H, Wicking C, Zaphiropoulous PG, Gailani MR, Shanley S, Chidambaram 544 A, et al. Mutations of the human homolog of Drosophila patched in the nevoid basal cell 545 carcinoma syndrome. Cell. 1996;85(6):841-51.

546 8. Aszterbaum M, Rothman A, Johnson RL, Fisher M, Xie J, Bonifas JM, et al. 547 Identification of mutations in the human PATCHED gene in sporadic basal cell 548 carcinomas and in patients with the basal cell nevus syndrome. The Journal of 549 investigative dermatology. 1998;110(6):885-8.

550 9. Raffel C, Jenkins RB, Frederick L, Hebrink D, Alderete B, Fults DW, et al. 551 Sporadic medulloblastomas contain PTCH mutations. Cancer Res. 1997;57(5):842-5.

552 10. Vorechovsky I, Tingby O, Hartman M, Stromberg B, Nister M, Collins VP, et al. 553 Somatic mutations in the human homologue of Drosophila patched in primitive 554 neuroectodermal tumours. Oncogene. 1997;15(3):361-6.

555 11. Tostar U, Malm CJ, Meis-Kindblom JM, Kindblom LG, Toftgard R, Unden AB. 556 Deregulation of the hedgehog signalling pathway: a possible role for the PTCH and 557 SUFU genes in human rhabdomyoma and rhabdomyosarcoma development. J Pathol. 558 2006;208(1):17-25.

559 12. Aavikko M, Li SP, Saarinen S, Alhopuro P, Kaasinen E, Morgunova E, et al. Loss 560 of SUFU function in familial multiple meningioma. Am J Hum Genet. 2012;91(3):520-6. 
13. Taylor MD, Liu L, Raffel C, Hui CC, Mainprize TG, Zhang X, et al. Mutations in SUFU predispose to medulloblastoma. Nat Genet. 2002;31(3):306-10.

14. Brastianos PK, Horowitz PM, Santagata S, Jones RT, McKenna A, Getz G, et al. Genomic sequencing of meningiomas identifies oncogenic SMO and AKT1 mutations. Nat Genet. 2013;45(3):285-9.

15. Sweeney RT, McClary AC, Myers BR, Biscocho J, Neahring L, Kwei KA, et al. Identification of recurrent SMO and BRAF mutations in ameloblastomas. Nat Genet. 2014;46(7):722-5.

16. Clark VE, Erson-Omay EZ, Serin A, Yin J, Cotney J, Ozduman K, et al. Genomic analysis of non-NF2 meningiomas reveals mutations in TRAF7, KLF4, AKT1, and SMO. Science. 2013;339(6123):1077-80.

17. Xie J, Murone M, Luoh SM, Ryan A, Gu Q, Zhang C, et al. Activating Smoothened mutations in sporadic basal-cell carcinoma. Nature. 1998;391(6662):90-2.

18. Reifenberger J, Wolter M, Weber RG, Megahed M, Ruzicka T, Lichter P, et al. Missense mutations in $\mathrm{SMOH}$ in sporadic basal cell carcinomas of the skin and primitive neuroectodermal tumors of the central nervous system. Cancer Res. 1998;58(9):1798803.

19. Northcott PA, Hielscher T, Dubuc A, Mack S, Shih D, Remke M, et al. Pediatric and adult sonic hedgehog medulloblastomas are clinically and molecularly distinct. Acta Neuropathol. 2011;122(2):231-40.

20. Northcott PA, Nakahara Y, Wu X, Feuk L, Ellison DW, Croul S, et al. Multiple recurrent genetic events converge on control of histone lysine methylation in medulloblastoma. Nat Genet. 2009;41(4):465-72.

21. Lam CW, Xie J, To KF, Ng HK, Lee KC, Yuen NW, et al. A frequent activated smoothened mutation in sporadic basal cell carcinomas. Oncogene. 1999;18(3):833-6.

22. Goodrich LV, Milenkovic L, Higgins KM, Scott MP. Altered neural cell fates and medulloblastoma in mouse patched mutants. Science. 1997;277(5329):1109-13.

23. Brugieres L, Remenieras A, Pierron G, Varlet P, Forget S, Byrde V, et al. High frequency of germline SUFU mutations in children with desmoplastic/nodular medulloblastoma younger than 3 years of age. J Clin Oncol. 2012;30(17):2087-93.

24. Barreto DC, Gomez RS, Bale AE, Boson WL, De Marco L. PTCH gene mutations in odontogenic keratocysts. J Dent Res. 2000;79(6):1418-22.

25. Shimada Y, Katsube K, Kabasawa Y, Morita K, Omura K, Yamaguchi A, et al. Integrated genotypic analysis of hedgehog-related genes identifies subgroups of keratocystic odontogenic tumor with distinct clinicopathological features. PLoS One. 2013;8(8):e70995. 
26. Robarge KD, Brunton SA, Castanedo GM, Cui Y, Dina MS, Goldsmith R, et al. GDC-0449-a potent inhibitor of the hedgehog pathway. Biorg Med Chem Lett. 2009;19(19):5576-81.

27. Pan S, Wu X, Jiang J, Gao W, Wan Y, Cheng D, et al. Discovery of NVPLDE225, a Potent and Selective Smoothened Antagonist. ACS Med Chem Lett. 2010;1(3):130-4.

28. Axelson M, Liu K, Jiang X, He K, Wang J, Zhao H, et al. U.S. Food and Drug Administration approval: vismodegib for recurrent, locally advanced, or metastatic basal cell carcinoma. Clin Cancer Res. 2013;19(9):2289-93.

29. Administration USFaD. Sonidegib 2015 [Available from:

http://www.fda.gov/Drugs/InformationOnDrugs/ApprovedDrugs/ucm455865.htm.

30. Munchhof MJ, Li Q, Shavnya A, Borzillo GV, Boyden TL, Jones CS, et al. Discovery of PF-04449913, a Potent and Orally Bioavailable Inhibitor of Smoothened. ACS Med Chem Lett. 2012;3(2):106-11.

31. FDA approves new treatment for patients with acute myeloid leukemia [press release]. 11/21/2018 2018.

32. Yauch RL, Gould SE, Scales SJ, Tang T, Tian H, Ahn CP, et al. A paracrine requirement for hedgehog signalling in cancer. Nature. 2008;455(7211):406-10.

33. Tian H, Callahan CA, DuPree KJ, Darbonne WC, Ahn CP, Scales SJ, et al. Hedgehog signaling is restricted to the stromal compartment during pancreatic carcinogenesis. Proc Natl Acad Sci U S A. 2009;106(11):4254-9.

34. Theunissen JW, de Sauvage FJ. Paracrine Hedgehog signaling in cancer. Cancer Res. 2009;69(15):6007-10.

35. Olive KP, Jacobetz MA, Davidson CJ, Gopinathan A, Mclntyre D, Honess D, et al. Inhibition of Hedgehog signaling enhances delivery of chemotherapy in a mouse model of pancreatic cancer. Science. 2009;324(5933):1457-61.

36. Rhim AD, Oberstein PE, Thomas DH, Mirek ET, Palermo CF, Sastra SA, et al. Stromal elements act to restrain, rather than support, pancreatic ductal adenocarcinoma. Cancer Cell. 2014;25(6):735-47.

37. Lee JJ, Perera RM, Wang H, Wu DC, Liu XS, Han S, et al. Stromal response to Hedgehog signaling restrains pancreatic cancer progression. Proc Natl Acad Sci U S A. 2014;111(30):E3091-100.

38. Shin K, Lim A, Odegaard JI, Honeycutt JD, Kawano S, Hsieh MH, et al. Cellular origin of bladder neoplasia and tissue dynamics of its progression to invasive carcinoma. Nat Cell Biol. 2014;16(5):469-78. 
39. Shin K, Lim A, Zhao C, Sahoo D, Pan Y, Spiekerkoetter E, et al. Hedgehog signaling restrains bladder cancer progression by eliciting stromal production of urothelial differentiation factors. Cancer Cell. 2014;26(4):521-33.

40. Gerling M, Buller NV, Kirn LM, Joost S, Frings O, Englert B, et al. Stromal Hedgehog signalling is downregulated in colon cancer and its restoration restrains tumour growth. Nature communications. 2016;7:12321.

41. Yang Z, Peng YC, Gopalan A, Gao D, Chen Y, Joyner AL. Stromal hedgehog signaling maintains smooth muscle and hampers micro-invasive prostate cancer. Disease models \& mechanisms. 2017;10(1):39-52.

42. Park KS, Martelotto LG, Peifer M, Sos ML, Karnezis AN, Mahjoub MR, et al. A crucial requirement for Hedgehog signaling in small cell lung cancer. Nat Med. 2011;17(11):1504-8.

43. Szczepny A, Rogers S, Jayasekara WSN, Park K, McCloy RA, Cochrane CR, et al. The role of canonical and non-canonical Hedgehog signaling in tumor progression in a mouse model of small cell lung cancer. Oncogene. 2017;36(39):5544-50.

44. Belani CP, Dahlberg SE, Rudin CM, Fleisher M, Chen HX, Takebe N, et al. Three-arm randomized phase II study of cisplatin and etoposide (CE) versus CE with either vismodegib $(\mathrm{V})$ or cixutumumab $(\mathrm{Cx})$ for patients with extensive stage-small cell lung cancer (ES-SCLC) (ECOG 1508). J Clin Oncol. 2013;31(suppl):abstr 7508.

45. Justilien V, Walsh MP, Ali SA, Thompson EA, Murray NR, Fields AP. The PRKCI and SOX2 oncogenes are coamplified and cooperate to activate Hedgehog signaling in lung squamous cell carcinoma. Cancer Cell. 2014;25(2):139-51.

46. Buglino JA, Resh MD. Hhat is a palmitoylacyl transferase with specificity for Npalmitoylation of sonic hedgehog. J Biol Chem. 2008.

47. Pepinsky RB, Zeng C, Wen D, Rayhorn P, Baker DP, Williams KP, et al. Identification of a palmitic acid-modified form of human Sonic hedgehog. J Biol Chem. 1998;273(22):14037-45.

48. Chamoun Z, Mann RK, Nellen D, von Kessler DP, Bellotto M, Beachy PA, et al. Skinny hedgehog, an acyltransferase required for palmitoylation and activity of the hedgehog signal. Science. 2001;293(5537):2080-4.

49. Kasiri S, Shao C, Chen B, Wilson AN, Yenerall P, Timmons BC, et al. GLI1 blockade potentiates the antitumor activity of PI3K antagonists in lung squamous cell carcinoma. Cancer Res. 2017.

50. Po A, Silvano M, Miele E, Capalbo C, Eramo A, Salvati V, et al. Noncanonical GLI1 signaling promotes stemness features and in vivo growth in lung adenocarcinoma. Oncogene. 2017;36(32):4641-52. 
668

669

670

671

672

673

674

675

676

677

678

679

680

681

682

683

684

685

686

687

688

689

690

691

692

693

694

695

696

697

698

699

700

701

51. Bitgood MJ, McMahon AP. Hedgehog and Bmp genes are coexpressed at many diverse sites of cell-cell interaction in the mouse embryo. Dev Biol. 1995;172(1):126-38.

52. Pepicelli CV, Lewis PM, McMahon AP. Sonic hedgehog regulates branching morphogenesis in the mammalian lung. Current biology : CB. 1998;8(19):1083-6.

53. Bellusci S, Furuta Y, Rush MG, Henderson R, Winnier G, Hogan BL. Involvement of Sonic hedgehog (Shh) in mouse embryonic lung growth and morphogenesis. Development. 1997;124(1):53-63.

54. Miller LA, Wert SE, Whitsett JA. Immunolocalization of sonic hedgehog (Shh) in developing mouse lung. J Histochem Cytochem. 2001;49(12):1593-604.

55. Peng T, Frank DB, Kadzik RS, Morley MP, Rathi KS, Wang T, et al. Hedgehog actively maintains adult lung quiescence and regulates repair and regeneration. Nature. 2015;526(7574):578-82.

56. Wang C, de Mochel NSR, Christenson SA, Cassandras M, Moon R, Brumwell AN, et al. Expansion of hedgehog disrupts mesenchymal identity and induces emphysema phenotype. J Clin Invest. 2018;128(10):4343-58.

57. Bermudez O, Hennen E, Koch I, Lindner M, Eickelberg O. Gli1 mediates lung cancer cell proliferation and Sonic Hedgehog-dependent mesenchymal cell activation. PLoS One. 2013;8(5):e63226.

58. Gyorffy B, Surowiak P, Budczies J, Lanczky A. Online survival analysis software to assess the prognostic value of biomarkers using transcriptomic data in non-small-cell lung cancer. PLoS One. 2013;8(12):e82241.

59. Szasz AM, Lanczky A, Nagy A, Forster S, Hark K, Green JE, et al. Crossvalidation of survival associated biomarkers in gastric cancer using transcriptomic data of 1,065 patients. Oncotarget. 2016;7(31):49322-33.

60. Lauth M, Bergstrom A, Shimokawa T, Tostar U, Jin Q, Fendrich V, et al.

DYRK1B-dependent autocrine-to-paracrine shift of Hedgehog signaling by mutant RAS. Nat Struct Mol Biol. 2010;17(6):718-25.

61. Taipale J, Chen JK, Cooper MK, Wang B, Mann RK, Milenkovic L, et al. Effects of oncogenic mutations in Smoothened and Patched can be reversed by cyclopamine. Nature. 2000;406(6799):1005-9.

62. Maity T, Fuse N, Beachy PA. Molecular mechanisms of Sonic hedgehog mutant effects in holoprosencephaly. Proc Natl Acad Sci U S A. 2005;102(47):17026-31.

63. Chen JK, Taipale J, Cooper MK, Beachy PA. Inhibition of Hedgehog signaling by direct binding of cyclopamine to Smoothened. Genes Dev. 2002;16(21):2743-8. 
64. Ericson J, Morton S, Kawakami A, Roelink H, Jessell TM. Two critical periods of Sonic Hedgehog signaling required for the specification of motor neuron identity. Cell. 1996;87(4):661-73.

\section{Maun HR, Wen X, Lingel A, de Sauvage FJ, Lazarus RA, Scales SJ, et al.} Hedgehog Pathway Antagonist 5E1 Binds Hedgehog at the Pseudo-active Site. J Biol Chem. 2010;285(34):26570-80.

66. Echelard Y, Epstein DJ, St-Jacques B, Shen L, Mohler J, McMahon JA, et al. Sonic hedgehog, a member of a family of putative signaling molecules, is implicated in the regulation of CNS polarity. Cell. 1993;75(7):1417-30.

67. Roelink H, Augsburger A, Heemskerk J, Korzh V, Norlin S, Ruiz i Altaba A, et al. Floor plate and motor neuron induction by vhh-1, a vertebrate homolog of hedgehog expressed by the notochord. Cell. 1994;76(4):761-75.

68. Marti E, Takada R, Bumcrot DA, Sasaki H, McMahon AP. Distribution of Sonic hedgehog peptides in the developing chick and mouse embryo. Development. 1995;121(8):2537-47.

69. Roelink H, Porter JA, Chiang C, Tanabe Y, Chang DT, Beachy PA, et al. Floor plate and motor neuron induction by different concentrations of the amino-terminal cleavage product of sonic hedgehog autoproteolysis. Cell. 1995;81(3):445-55.

70. Jackson EL, Olive KP, Tuveson DA, Bronson R, Crowley D, Brown M, et al. The differential effects of mutant p53 alleles on advanced murine lung cancer. Cancer Res. 2005;65(22):10280-8.

71. Muzumdar MD, Tasic B, Miyamichi K, Li L, Luo L. A global double-fluorescent Cre reporter mouse. Genesis. 2007;45(9):593-605.

72. Lewis PM, Dunn MP, McMahon JA, Logan M, Martin JF, St-Jacques B, et al. Cholesterol modification of sonic hedgehog is required for long-range signaling activity and effective modulation of signaling by Ptc1. Cell. 2001;105(5):599-612.

73. Wang LC, Liu ZY, Gambardella L, Delacour A, Shapiro R, Yang J, et al. Regular articles: conditional disruption of hedgehog signaling pathway defines its critical role in hair development and regeneration. J Invest Dermatol. 2000;114(5):901-8.

74. Paladini RD, Saleh J, Qian C, Xu GX, Rubin LL. Modulation of hair growth with small molecule agonists of the hedgehog signaling pathway. J Invest Dermatol. 2005;125(4):638-46.

75. Sanchez-Rivera FJ, Papagiannakopoulos T, Romero R, Tammela T, Bauer MR, Bhutkar A, et al. Rapid modelling of cooperating genetic events in cancer through somatic genome editing. Nature. 2014;516(7531):428-31. 
737 76. Cha YJ, Shim HS. Biology of invasive mucinous adenocarcinoma of the lung.

738 Transl Lung Cancer Res. 2017;6(5):508-12.

739 77. Pola R, Ling LE, Silver M, Corbley MJ, Kearney M, Blake Pepinsky R, et al. The 740 morphogen Sonic hedgehog is an indirect angiogenic agent upregulating two families of 741 angiogenic growth factors. Nat Med. 2001;7(6):706-11.

742 78. Byrd N, Becker S, Maye P, Narasimhaiah R, St-Jacques B, Zhang X, et al. 743 Hedgehog is required for murine yolk sac angiogenesis. Development.

744 2002;129(2):361-72.

745

746

747

748

749

750

751

752

753

754

755

756

757

758

759

760

761

762

763

764

765

766

767

768

769

770

771

772

79. Li W, Miao S, Miao M, Li R, Cao X, Zhang K, et al. Hedgehog Signaling Activation in Hepatic Stellate Cells Promotes Angiogenesis and Vascular Mimicry in Hepatocellular Carcinoma. Cancer Invest. 2016;34(9):424-30.

80. Di Mauro C, Rosa R, D'Amato V, Ciciola P, Servetto A, Marciano R, et al. Hedgehog signalling pathway orchestrates angiogenesis in triple-negative breast cancers. Br J Cancer. 2017;116(11):1425-35.

81. Chandel NS, McClintock DS, Feliciano CE, Wood TM, Melendez JA, Rodriguez AM, et al. Reactive oxygen species generated at mitochondrial complex III stabilize hypoxia-inducible factor-1alpha during hypoxia: a mechanism of $\mathrm{O} 2$ sensing. J Biol Chem. 2000;275(33):25130-8.

82. Guzy RD, Hoyos B, Robin E, Chen H, Liu L, Mansfield KD, et al. Mitochondrial complex III is required for hypoxia-induced ROS production and cellular oxygen sensing. Cell Metab. 2005;1(6):401-8.

83. St Clair DK, Wan XS, Oberley TD, Muse KE, St Clair WH. Suppression of radiation-induced neoplastic transformation by overexpression of mitochondrial superoxide dismutase. Mol Carcinog. 1992;6(4):238-42.

84. Safford SE, Oberley TD, Urano M, St Clair DK. Suppression of fibrosarcoma metastasis by elevated expression of manganese superoxide dismutase. Cancer Res. 1994;54(16):4261-5.

85. Weinberg F, Hamanaka R, Wheaton WW, Weinberg S, Joseph J, Lopez M, et al. Mitochondrial metabolism and ROS generation are essential for Kras-mediated tumorigenicity. Proc Natl Acad Sci U S A. 2010;107(19):8788-93.

86. Schneider CA, Rasband WS, Eliceiri KW. NIH Image to ImageJ: 25 years of image analysis. Nat Methods. 2012;9(7):671-5.

87. Schindelin J, Arganda-Carreras I, Frise E, Kaynig V, Longair M, Pietzsch T, et al. Fiji: an open-source platform for biological-image analysis. Nat Methods. 2012;9(7):676-

88. Li Z, Yang J, Huang $\mathrm{H}$. Oxidative stress induces $\mathrm{H} 2 \mathrm{AX}$ phosphorylation in human spermatozoa. FEBS Lett. 2006;580(26):6161-8. 
89. Tanaka T, Halicka HD, Traganos F, Darzynkiewicz Z. Phosphorylation of histone H2AX on Ser 139 and activation of ATM during oxidative burst in phorbol ester-treated human leukocytes. Cell Cycle. 2006;5(22):2671-5.

90. Lim A, Shin K, Zhao C, Kawano S, Beachy PA. Spatially restricted Hedgehog signalling regulates HGF-induced branching of the adult prostate. Nat Cell Biol. 2014;16(12):1135-45.

91. Morrisey EE, Hogan BL. Preparing for the first breath: genetic and cellular mechanisms in lung development. Dev Cell. 2010;18(1):8-23.

92. Kugler MC, Joyner AL, Loomis CA, Munger JS. Sonic hedgehog signaling in the lung. From development to disease. Am J Respir Cell Mol Biol. 2015;52(1):1-13.

93. van den Brink GR, Bleuming SA, Hardwick JC, Schepman BL, Offerhaus GJ, Keller JJ, et al. Indian Hedgehog is an antagonist of Wnt signaling in colonic epithelial cell differentiation. Nat Genet. 2004;36(3):277-82.

94. Lee JJ, Rothenberg ME, Seeley ES, Zimdahl B, Kawano S, Lu WJ, et al. Control of inflammation by stromal Hedgehog pathway activation restrains colitis. Proc Natl Acad Sci U S A. 2016;113(47):E7545-E53.

95. Colnot C, de la Fuente L, Huang S, Hu D, Lu C, St-Jacques B, et al. Indian hedgehog synchronizes skeletal angiogenesis and perichondrial maturation with cartilage development. Development. 2005;132(5):1057-67.

96. Mathew E, Zhang Y, Holtz AM, Kane KT, Song JY, Allen BL, et al. Dosagedependent regulation of pancreatic cancer growth and angiogenesis by hedgehog signaling. Cell reports. 2014;9(2):484-94 .

97. Chung WJ, Daemen A, Cheng JH, Long JE, Cooper JE, Wang BE, et al. Kras mutant genetically engineered mouse models of human cancers are genomically heterogeneous. Proc Natl Acad Sci U S A. 2017;114(51):E10947-E55.

98. Eser S, Reiff N, Messer M, Seidler B, Gottschalk K, Dobler M, et al. Selective requirement of PI3K/PDK1 signaling for Kras oncogene-driven pancreatic cell plasticity and cancer. Cancer Cell. 2013;23(3):406-20.

99. Reczek CR, Chandel NS. The Two Faces of Reactive Oxygen Species in Cancer. Annual Review of Cancer Biology. 2017;1(1):79-98.

100. Sabharwal SS, Schumacker PT. Mitochondrial ROS in cancer: initiators, amplifiers or an Achilles' heel? Nat Rev Cancer. 2014;14(11):709-21.

101. Lee SR, Yang KS, Kwon J, Lee C, Jeong W, Rhee SG. Reversible inactivation of the tumor suppressor PTEN by H2O2. J Biol Chem. 2002;277(23):20336-42. 
807 102. Liou GY, Doppler H, DelGiorno KE, Zhang L, Leitges M, Crawford HC, et al. 808 Mutant KRas-Induced Mitochondrial Oxidative Stress in Acinar Cells Upregulates EGFR 809 Signaling to Drive Formation of Pancreatic Precancerous Lesions. Cell reports.

810 2016;14(10):2325-36.

811 103. Bell EL, Klimova TA, Eisenbart J, Moraes CT, Murphy MP, Budinger GR, et al. 812 The Qo site of the mitochondrial complex III is required for the transduction of hypoxic 813 signaling via reactive oxygen species production. J Cell Biol. 2007;177(6):1029-36.

814 104. Kim J, Aftab BT, Tang JY, Kim D, Lee AH, Rezaee M, et al. Itraconazole and 815 arsenic trioxide inhibit Hedgehog pathway activation and tumor growth associated with 816 acquired resistance to smoothened antagonists. Cancer Cell. 2013;23(1):23-34.

817 105. Shalem O, Sanjana NE, Hartenian E, Shi X, Scott DA, Mikkelson T, et al. 818 Genome-scale CRISPR-Cas9 knockout screening in human cells. Science.

$819 \quad 2014 ; 343(6166): 84-7$.

820 106. DuPage M, Dooley AL, Jacks T. Conditional mouse lung cancer models using 821 adenoviral or lentiviral delivery of Cre recombinase. Nat Protoc. 2009;4(7):1064-72.

822 107. Kim CF, Jackson EL, Woolfenden AE, Lawrence S, Babar I, Vogel S, et al. 823 Identification of bronchioalveolar stem cells in normal lung and lung cancer. Cell. $8242005 ; 121(6): 823-35$. 


\section{Figure Legends}

827 Fig. 1 SHH in human lung adenocarcinoma. a-d Survival analyses of lung 828 adenocarcinoma patients with high and low SHH mRNA expression from Kaplan-Meier 829 Plotter database $(58,59) . n=720$ patients. High and low mRNA expression is relative to 830 median expression. a Kaplan-Meier plot by univariate analysis of overall survival $(P=$ $8310.0006)$ is shown. b Multivariate analysis of overall survival is shown with stage, gender, 832 smoking history, and Shh mRNA expression as variables. c Kaplan-Meier plot by 833 univariate analysis $(P=0.044)$ and $\mathbf{d}$ multivariate analysis of progression free survival of 834 lung adenocarcinoma patients analogous to panels a and b. e Expression of $S H H$ 835 mRNA as measured by $\mathrm{qPCR}$ relative to a normal bronchial epithelial cell line 836 (HBEC7KT). Dashed line represents 4x expression relative to HBEC7KT. f Immunoblot of active $\mathrm{N}$-terminal $\mathrm{SHH}$ of high and low $\mathrm{SHH}$-expressing lung cancer cell lines from panel e. All qPCR data represent mean of triplicates +/-SD. g Relative Hh pathway activity of Shh-Light2 fibroblasts with an 8x-GLI-luciferase reporter is shown. Shh-Light2 cells were co-cultured with low SHH expressing HBEC7KT, a human normal lung

841 epithelial cell line, low SHH expressing H3122 LAD cell line, and high SHH-expressing 842 H23, H2887 and HCC44 LAD cell lines. Cell lines were treated with control vehicle, KAAD-cyclopamine $200 \mathrm{nM}$, and 5E1 $10 \mu \mathrm{g} / \mathrm{ml} .{ }^{* * *} P<0.001,{ }^{* * *} P<0.0001$.

Fig. 2 SHH does not affect tumor growth and survival in vivo. a Shh mRNA expression

847 situ hybridization. Red puncta indicate Shh mRNA. Scale bar is 50 micrometers. b 
849 recombinase (adeno-cre) infection ('KP' in panel) along with CD31-, CD45-, EpCAM+

850 lung epithelial cells of uninfected KP mice ('Wt' in panel) were FACS-sorted and Shh

851 mRNA levels were analyzed by qPCR. The data represents mean of duplicates +/-

852 s.e.m ( $\mathrm{n}=4$ lung lobes from 2 mice) for adeno-cre infected KPmTmG mice and mean of

853 triplicates +/- s.e.m ( $n=4$ lung lobes from 4 mice) for uninfected $K P$ mice. ${ }^{\star \star \star \star} P<0.0001$.

854 c Survival curves of $K P ; S h h^{+/+}, K P ; S h h^{f l /+}$, and $K P ; S h h^{f l / f l}$ mice after infection with adeno-

855 cre by intranasal inhalation are shown. KP;Shh ${ }^{+/+} \mathrm{n}=17, K P ; S h h^{f / /+} \mathrm{n}=18, K P ; S h h^{f / f l}$

$856 \mathrm{n}=17$. d EpCAM+;GFP+ lung epithelial cells of KPmTmG and KPmTmG;Shh ${ }^{\text {fl/fl }}$ mice 3

857 weeks after adeno-cre infection were FACS sorted and Shh mRNA levels were

858 measured by qPCR. The data represents mean of duplicates +/- s.e.m. $n=4$ lung lobes

859 from 2 mice per treatment arm. The expression levels were normalized to $S h h^{W T}$.

860

${ }^{\star \star * *} P<0.0001$. e Quantification of mean tumor area is shown. f Representative H\&E

861 images of left lung from $K P ; S h h^{+/+}, K P ; S h h^{f l /+}$, and $K P ; S h h^{f / f l}$ mice 10 weeks after

862 adeno-cre infection. Scale bars are 2 millimeters.

863

864

Fig. 3 Inhibition of stromal Hh pathway activation worsens survival with increased tumor

865 growth and metastases. a Schematic diagram of KP mice infection and treatment with

$8665 \mathrm{E} 1$ or $\operatorname{lgG}_{1}$ b, c Survival curves are shown of $K P$ mice treated with $5 \mathrm{E} 110 \mathrm{mg} / \mathrm{kg}$ twice

867 per week or corresponding $\lg _{1}$ dose starting b 2 weeks $\left(K P 5 \mathrm{E} 1 \mathrm{n}=18, K P \lg \mathrm{G}_{1} \mathrm{n}=18\right.$,

868

$\left.{ }^{* *} P=0.0002\right)$ and c 6 weeks $\left(K P 5 \mathrm{E} 1 \mathrm{n}=10, K P \lg \mathrm{G}_{1} \mathrm{n}=10, P=0.34\right)$ after tumor

869 initiation by intranasal administration of adeno-cre. d Fraction of mice with grossly

870 visible metastases from experiment in panel $b$ is shown. e, f Representative $H \& E$

871 images metastatic tumors in a e mediastinal lymph node and in $\mathbf{f}$ pleura invading the 
872 chest wall. Scale bars are 500 micrometers. g-j KP mice were treated with $5 \mathrm{E} 110$

$873 \mathrm{mg} / \mathrm{kg}$ twice per week or corresponding $\operatorname{lgG}_{1}$ dose for 8 weeks starting 2 weeks after

874 adeno-cre infection. g Quantification of mean tumor area is shown. Data represent

875 mean of $\operatorname{lgG}_{1}\left(\mathrm{n}=195\right.$ tumors) or $5 \mathrm{E} 1(\mathrm{n}=182$ tumors $)+/-$ s.e.m. ${ }^{* \star} P<0.01 . \mathbf{h}$, $\mathbf{i}$

876 Representative H\&E images of left lung of mice from panel $\mathrm{g}$. Scale bars in panels $\mathrm{h}$

877 and i are 2 and 2.5 millimeters respectively. j Percent of tumors with poor, moderate,

878 and well differentiated histologies are shown of KP LAD 10 weeks after adeno-cre

879 infection. Data represent mean of $\lg _{1}(\mathrm{n}=101$ tumors $)$ or $5 \mathrm{E} 1$ ( $\mathrm{n}=120$ tumors $)+/-$

880 s.e.m. k Representative H\&E images of poor, moderate, and well differentiated tumors

881 are shown. Scale bars are 100 micrometers.

882

883 Fig. $4 \mathrm{IHH}$ regulates the suppression of lung adenocarcinoma. a $\mathrm{Hh}$ pathway activity as

884

measured by $8 x$-GLI-luciferase reporter relative to PBS control in Shh-Light2 reporter

885 cells is shown. Shh-Light2 cells were treated with $1,2.5$, and $5 \mu \mathrm{g} / \mathrm{mL}$ of mouse $\mathrm{rlHH}$ or

$886 \mathrm{rSHH}$ in combination with $5 \mathrm{E} 1$ or $\lg \mathrm{G}_{1} 10 \mu \mathrm{g} / \mathrm{mL}$. PBS was used as a control vehicle for

$887 \mathrm{IHH}$ or SHH. b In situ hybridization for Ihh mRNA in LAD of KP mice is shown. Red 888 puncta indicate Ihh mRNA. Scale bar is 50 micrometers. c Shh and Ihh mRNA levels of

889 FACS sorted lung epithelial cells from KPmTmG mice 6 weeks after adeno-cre infection

890 is shown. mRNA was measured with qPCR. Data are mean of duplicate +/- s.e.m. $n=4$

891 mice. ${ }^{\star \star * *} P<0.0001$ d Bioluminescence images (BLI) are shown of lung tumors in $892 K P ; R o s a 26^{L S L-f L u c /+} 18$ weeks after infection with lentiviral pSECC-sg/hh or pSECC893 sgGFP. The second row shows BLI of mice 22-26 weeks after pSECC-sgGFP infection.

894 e Quantification of luminescence intensity is shown for pSECC-sg/hh and pSECC- 
895 896

897

898

899

900

901

902

903

904

905

906

907

908

909

910

911

912

913

914

915

916

sgGFP infected mice at 18 weeks. f Representative images of H\&E images of right upper lobes of pSECC-sg/hh and pSECC-sgGFP infected mice at 18 weeks. Scale bars are 2 millimeters.

Fig. $5 \mathrm{IHH}$ in human lung adenocarcinoma. a In situ hybridization for $I H H$ mRNA in human LAD is shown. Brown puncta indicate IHH mRNA. Arrowheads indicate areas of IHH mRNA staining in malignant cells. Scale bar is 50 micrometers. b Expression of IHH mRNA as measured by qPCR relative to a normal bronchial epithelial cell line (HBEC7KT). Dashed line represents 4x expression relative to HBEC7KT. c-e Survival analyses of lung adenocarcinoma patients with high and low $I H H$ mRNA expression from Kaplan-Meier Plotter database $(58,59) . n=673$ patients. High and low mRNA expression is relative to median expression. c Kaplan-Meier plot by univariate analysis of overall survival ( $P=0.0001)$ is shown. d Multivariate analysis of overall survival is shown with stage, gender, smoking history, and Ihh mRNA expression as variables. e Kaplan-Meier plot by univariate analysis $(P=0.0069)$ and $\mathbf{f}$ multivariate analysis of progression free survival of lung adenocarcinoma patients analogous to panels $\mathrm{c}$ and $\mathrm{d}$.

Fig. $6 \mathrm{IHH}$ loss inhibits angiogenesis and increases reactive oxygen species. a-d $K P$ mice were treated with 5E1 $10 \mathrm{mg} / \mathrm{kg}$ twice per week or corresponding $\lg _{1}$ dose for 8 weeks starting 2 weeks after infection a Quantification of vessel density (area of CD31 positive cells in tumor /tumor area) is shown. Data represent mean of $\lg _{1}$ ( $n=155$ tumors) or 5E1 ( $\mathrm{n}=169$ tumors) +/- s.e.m. ${ }^{* * *} \mathrm{P}<0.0001$. b Representative images of lung tumors of $K P$ mice stained for CD31 by IHC with DAB substrate. Scale bar is 500 
917 micrometers. c Fraction of $\gamma \mathrm{H} 2 \mathrm{AX}+$ nuclei $(\gamma \mathrm{H} 2 \mathrm{AX}+$ nuceli per tumor/total nuclei per 918 tumor) is shown. Data represent the mean of $\operatorname{lgG}_{1}(\mathrm{n}=86$ tumors) or $5 \mathrm{E} 1$ ( $\mathrm{n}=97$ 919 tumors) +/- s.e.m. ${ }^{* *} P<0.01$ d Representative images of lung tumors of $K P$ mice 920 stained for $\gamma \mathrm{H} 2 \mathrm{AX}$ by IHC. DAB was used as substrate. Scale bar is 100 micrometers e 921 Schematic diagram of survival study for panels $\mathrm{f}-\mathrm{h}$. $K P$ mice were infected with adeno922 cre by intranasal inhalation and treated with vehicle or N-Acetyl Cysteine (NAC) $923200 \mathrm{mg} / \mathrm{kg}$ i.p. once per day on days 12 and 13 after adeno-cre infection. From day 14, 924 mice were treated with 5E1 $10 \mathrm{mg} / \mathrm{kg}$ i.p. twice per week or corresponding $\operatorname{lgG}_{1}$ dose. 925 and NAC $1 \mathrm{~g} / \mathrm{L}$ supplemented in their drinking water. f Survival curves are shown of $K P$ 926 mice treated with $5 E 1$ and control vehicle $(n=8)$ or NAC $(n=9)$. ${ }^{\star *} P=0.0031$. g Survival 927 curves of $K P$ mice treated with $\operatorname{lgG}_{1}$ with control vehicle $(\mathrm{n}=8)$ or NAC $(\mathrm{n}=7, P=0.55)$. 928 starting 2 weeks after infection. $\mathbf{h}$ Fraction of mice with grossly visible metastases from 929 experiment in panel $\mathrm{f}$ is shown. i Quantification of mean lung tumor area of $K P$ mice 930 treated with 5E1 in combination with control or NAC for 8 weeks starting 2 weeks after 931 adeno-cre infection.. Data represent the mean of Ctl ( $n=64$ tumors) and NAC ( $n=85$ 932 tumors) +/- s.e.m. ${ }^{*} P<0.05$. j Representative H\&E images of left lung from panel i. 933 Scale bars are 2 millimeters. k Fraction of $\gamma \mathrm{H} 2 \mathrm{AX}+$ nuclei of tumors is shown. Data 934 represent the mean of $\mathrm{Ctl}\left(\mathrm{n}=87\right.$ tumors) and $\mathrm{NAC}(\mathrm{n}=82$ tumors $)+/-$ s.e.m. ${ }^{*} P<0.05$.

935 I Representative images of lung tumors of $K P$ mice from panel $k$ stained for $\gamma \mathrm{H} 2 \mathrm{AX}$ by 936 IHC. DAB was used as substrate. Scale bars are 100 micrometers. 

Fig. 1 certified by peer review) is the author/funder. All rights reserved. No reuse allowed without permission.

a

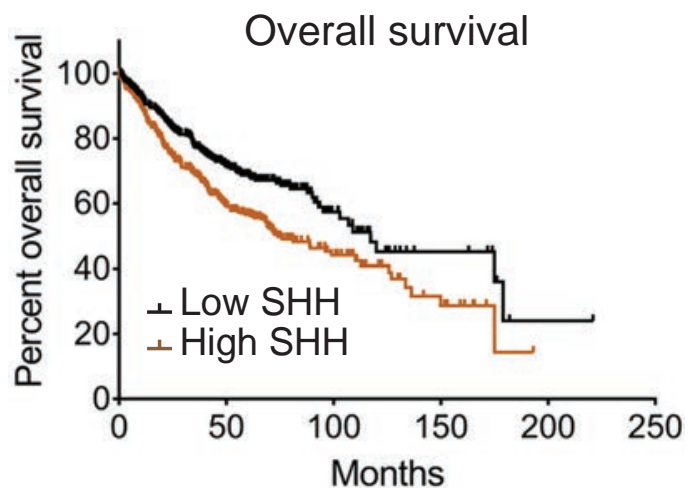

C

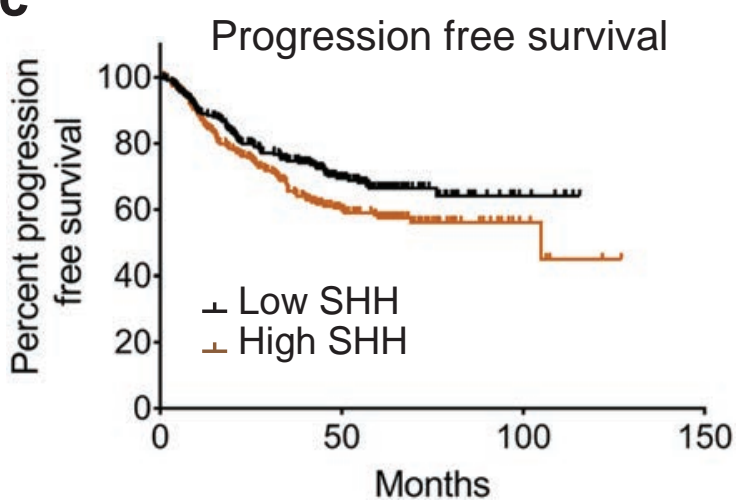

e

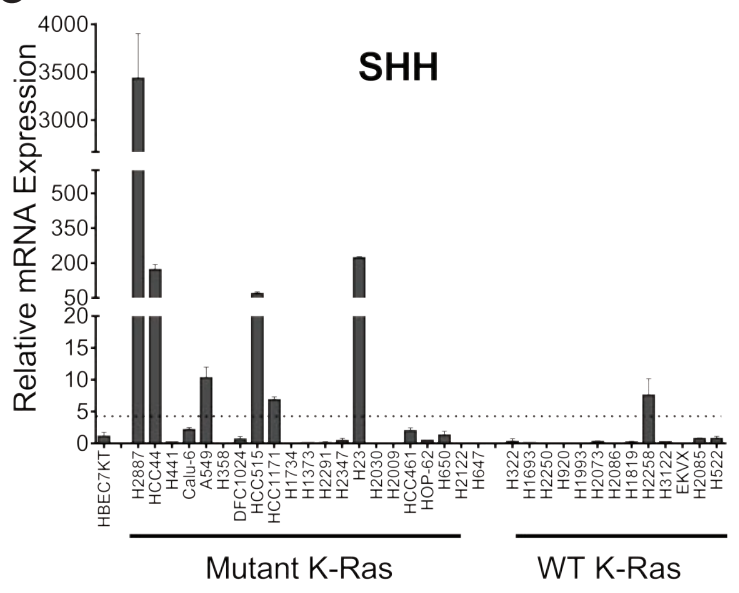

g

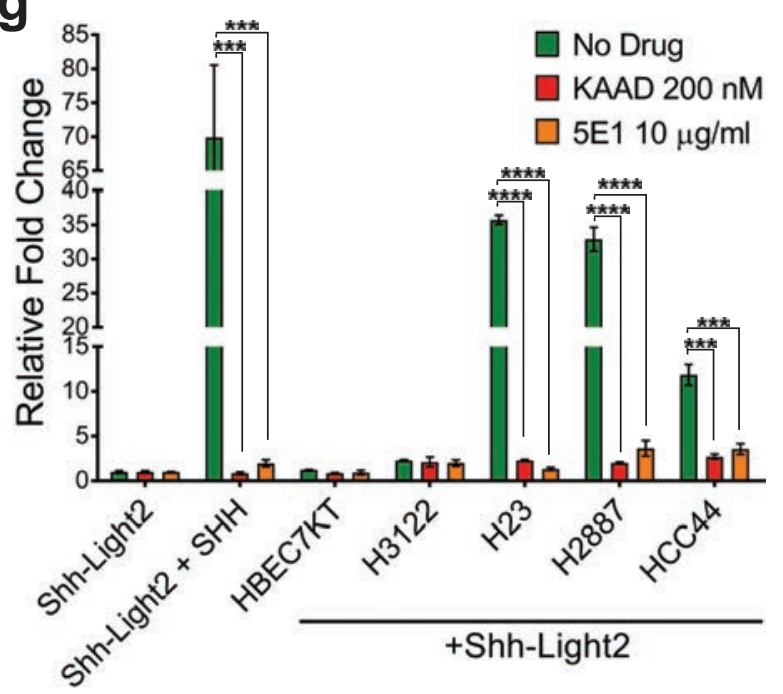

b

\begin{tabular}{|l||l|c|}
\hline \multicolumn{3}{|c|}{ Overall survival multivariate analysis } \\
& P value & Hazard Ratio \\
\hline Stage & $<10^{-16}$ & $2.48(1.8-3.41)$ \\
\hline Gender & 0.978 & $0.99(0.63-1.56)$ \\
\hline Smoking history & 0.0463 & $0.58(0.34-0.99)$ \\
\hline $\begin{array}{l}\text { SHH mRNA } \\
\text { expression }\end{array}$ & 0.0223 & $1.65(1.07-2.52)$ \\
\hline
\end{tabular}

d

\begin{tabular}{|l||l|l|}
\multicolumn{2}{|l|}{ Progression free survival multivariate analysis } \\
& P value & \multicolumn{1}{|c|}{ Hazard Ratio } \\
\hline Stage & $<10^{-16}$ & $2.3(1.72-3.09)$ \\
\hline Gender & 0.5888 & $1.12(0.74-1.7)$ \\
\hline Smoking history & 0.8177 & $0.95(0.61-1.48)$ \\
\hline $\begin{array}{l}\text { SHH mRNA } \\
\text { expression }\end{array}$ & 0.1719 & $1.29(0.9-1.85)$ \\
\hline
\end{tabular}

f

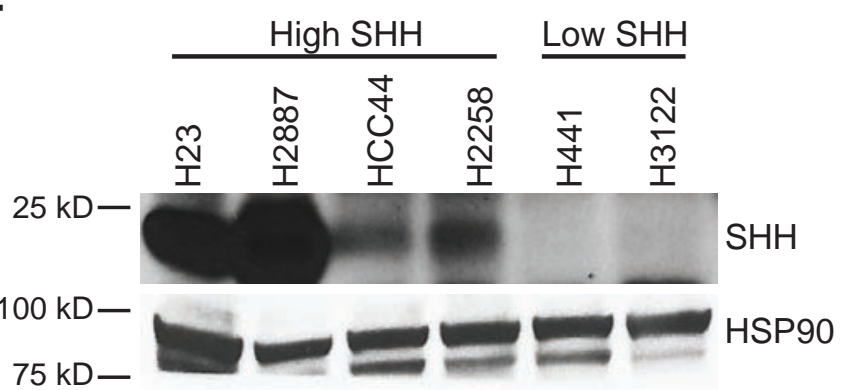


Fig. 2 certified by peer review) is the author/funder. All rights reserved. No reuse allowed without permission.

a

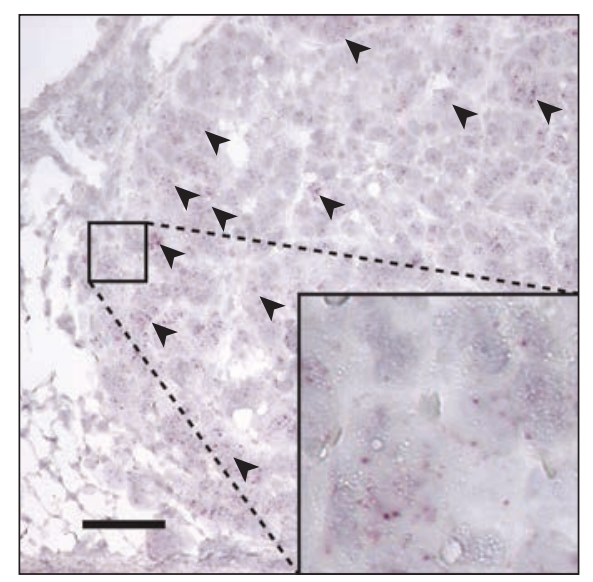

C

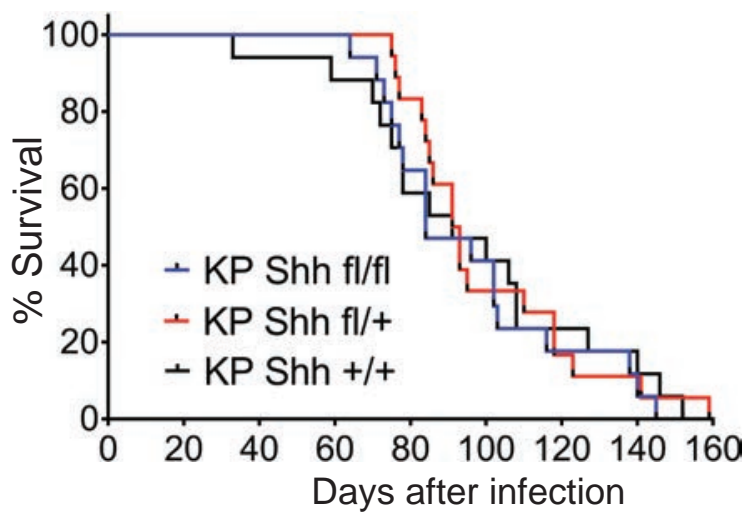

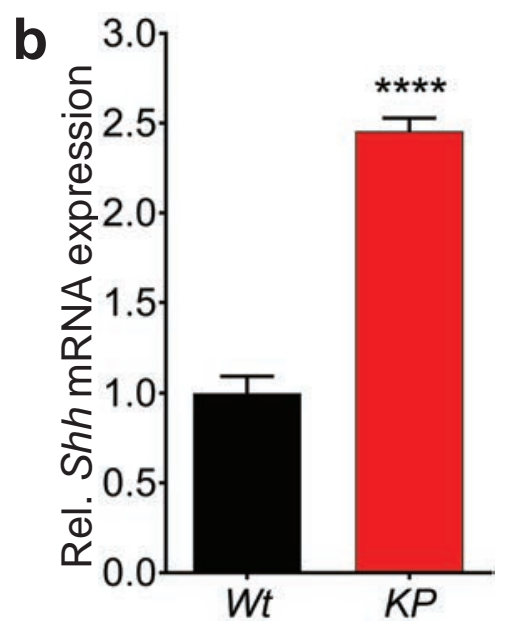

d

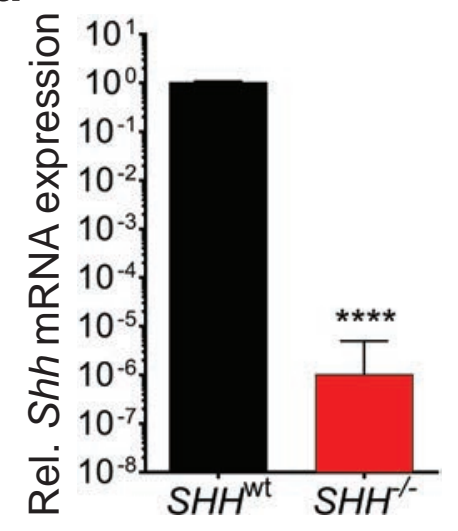

e

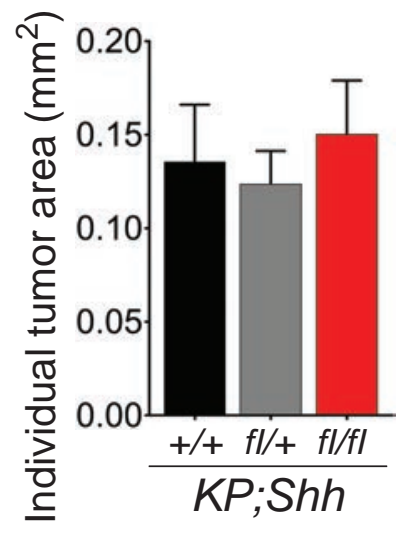

f
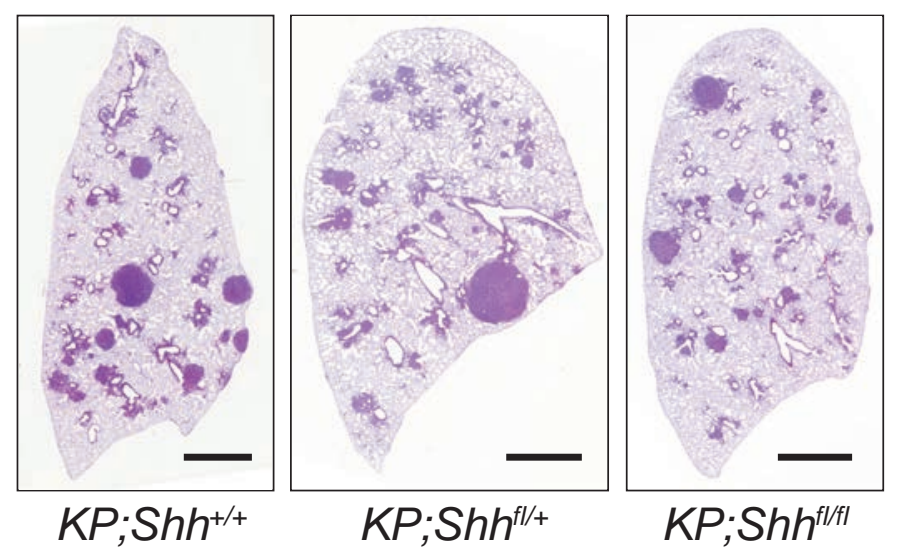
Fig. 3 certified by peer review) is the author/funder. All rights reserved. No reuse allowed without permission.

a

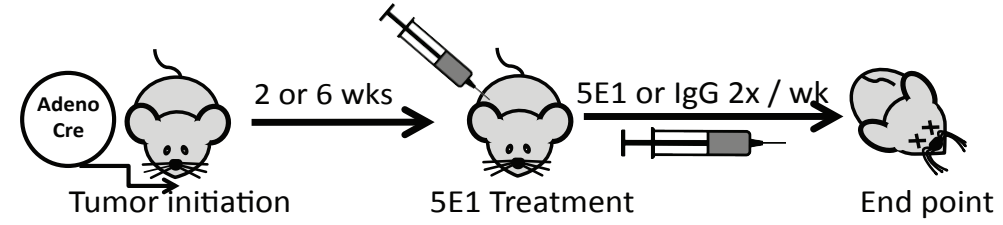

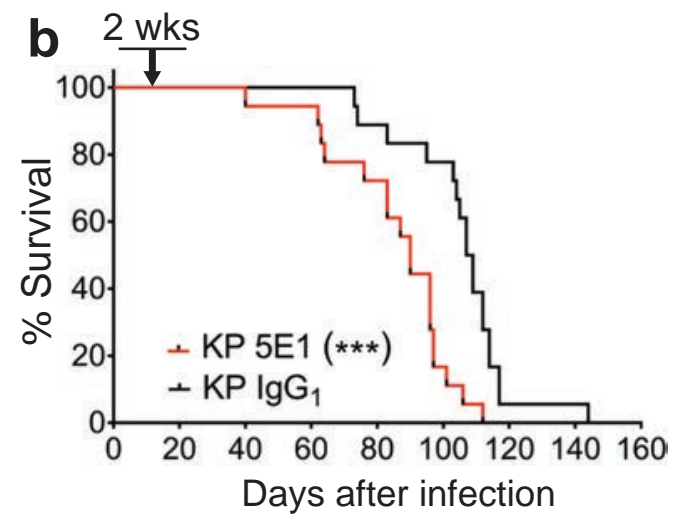

d

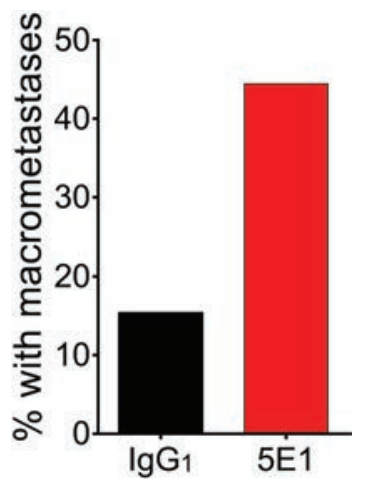

g

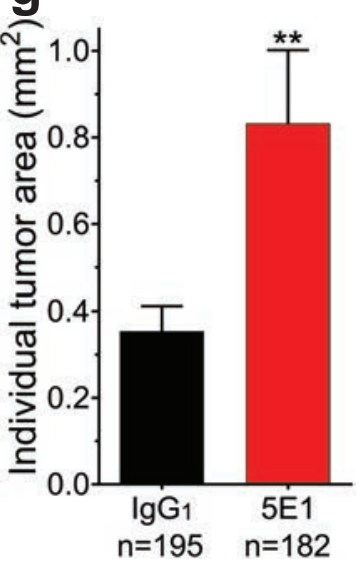

k

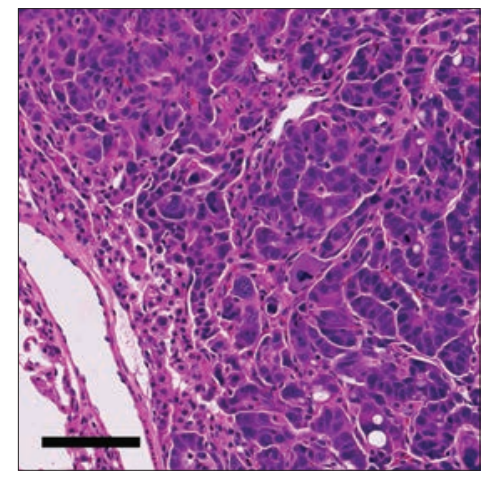

Poor
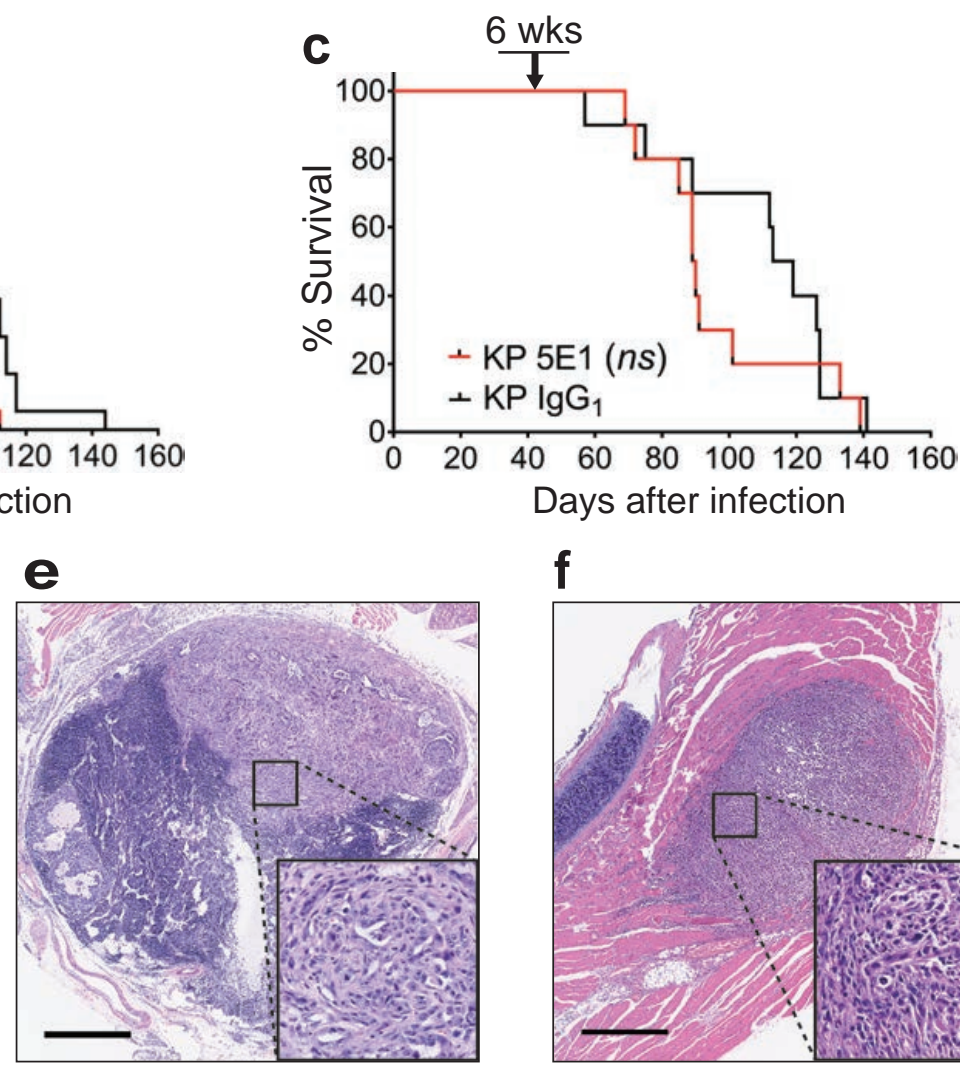

\section{h}

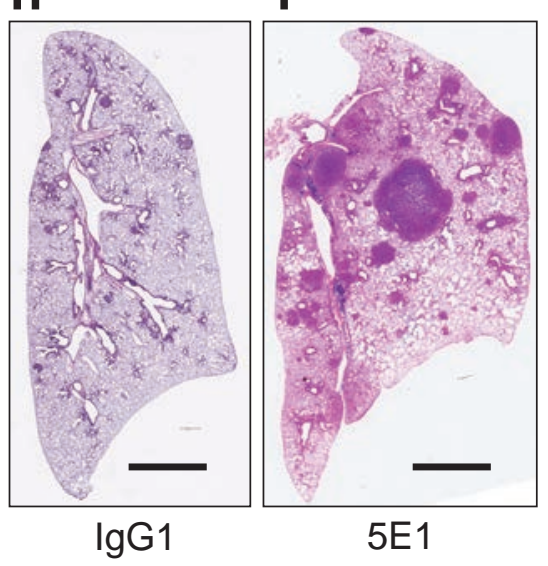

$5 \mathrm{E} 1$

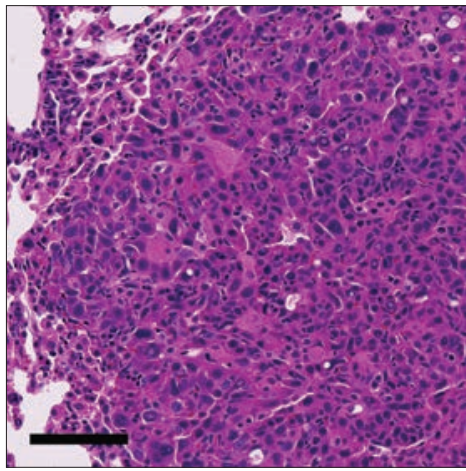

Moderate

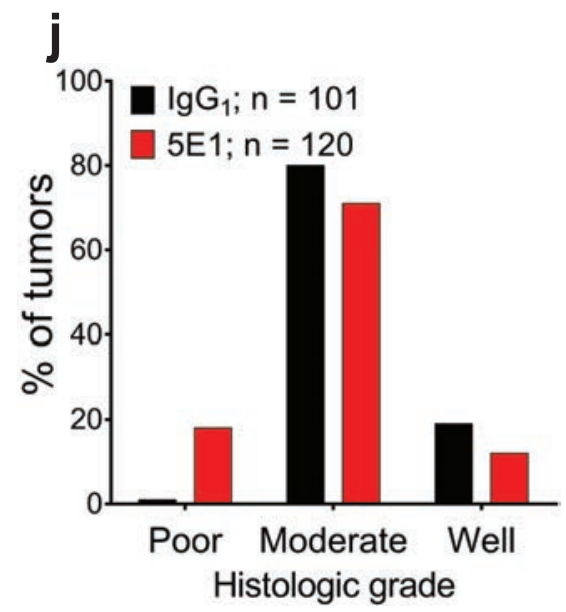

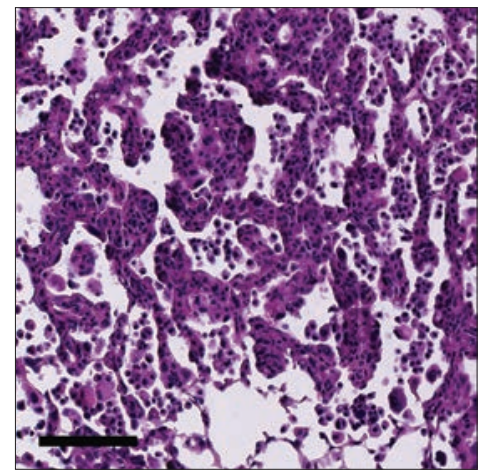

Well 
Fig. 4 certified by peer review) is the author/funder. All rights reserved. No reuse allowed without permission.

a

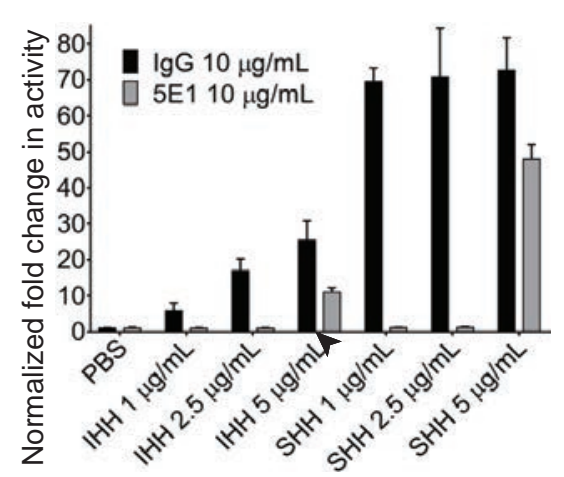

b

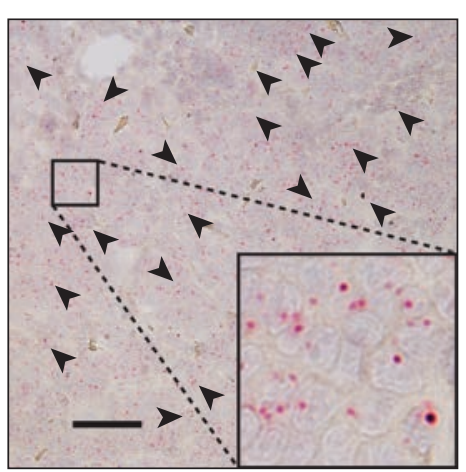

C

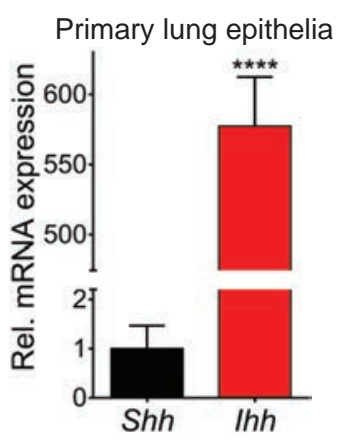

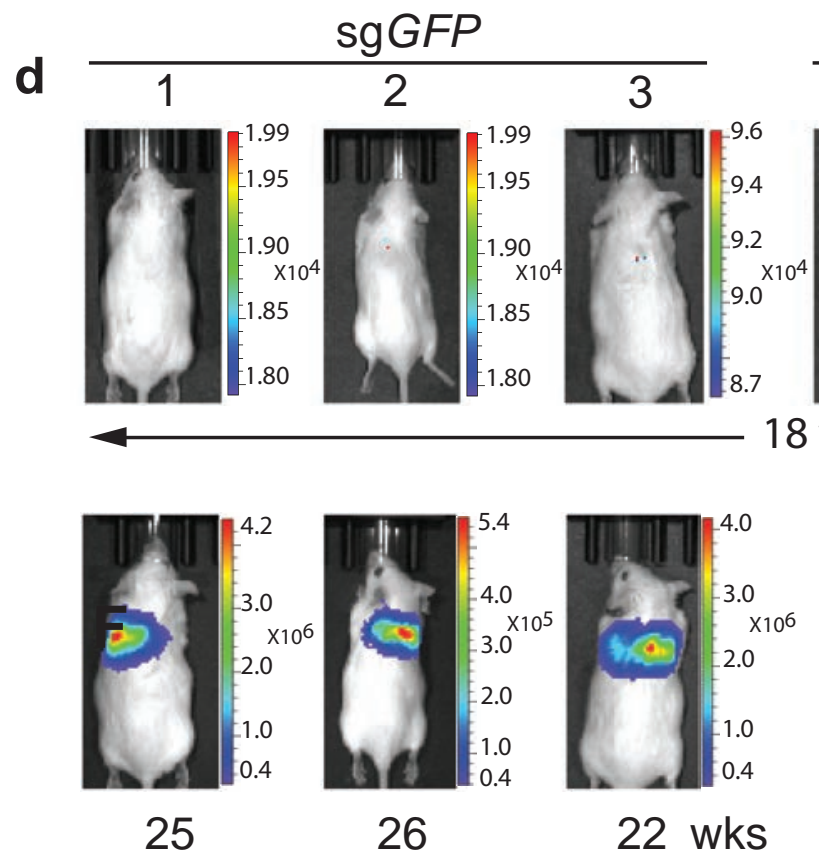

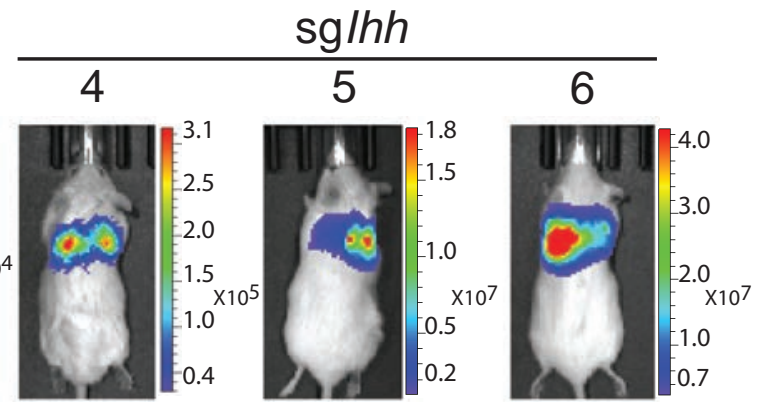

18 wks

\section{f}
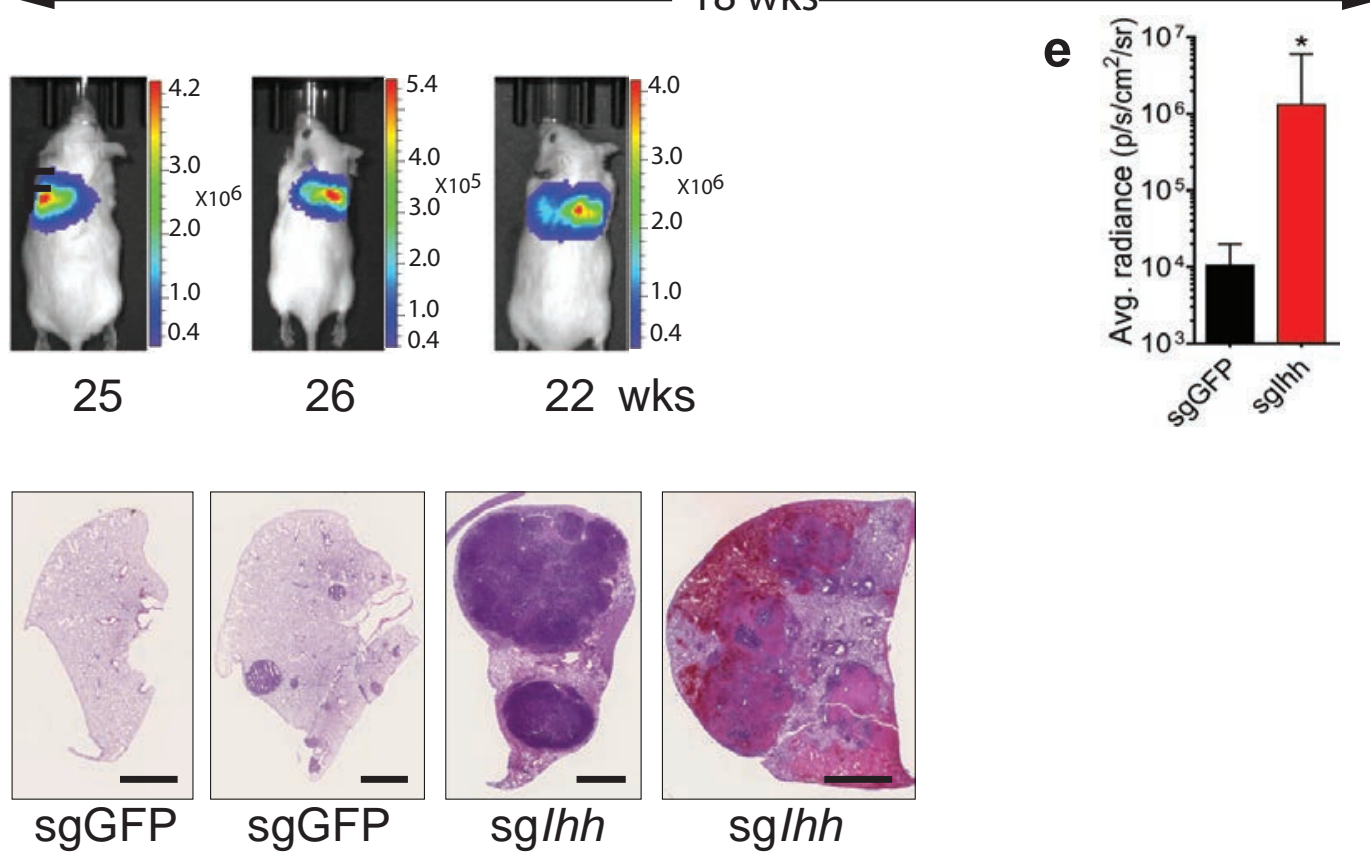
Fig. 5

a

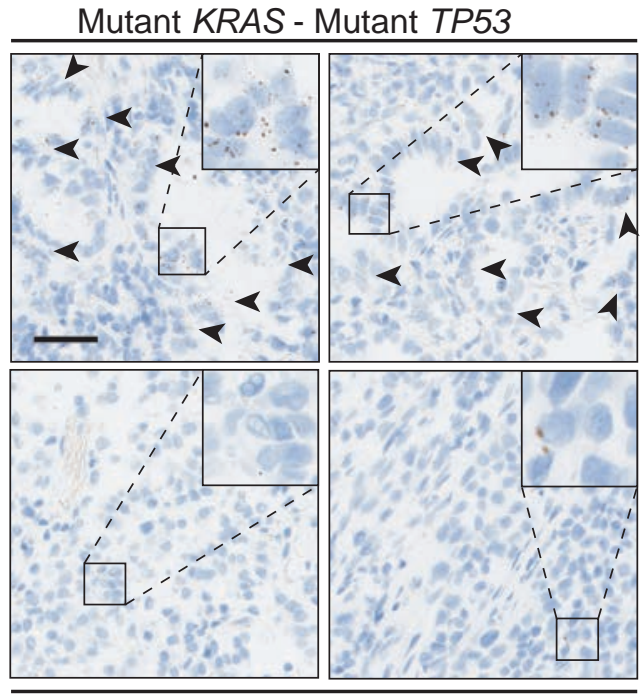

WT KRAS - WT TP53

C

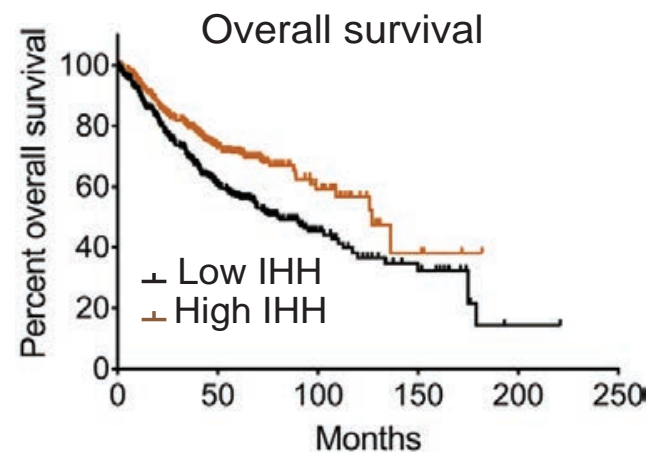

b

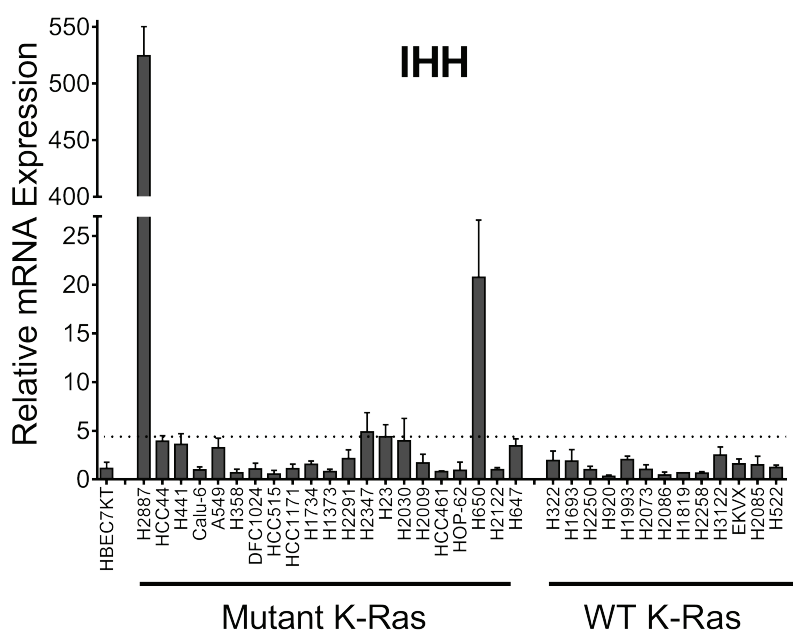

d

\begin{tabular}{|l||l|l|}
\hline \multicolumn{3}{|c|}{ Overall survival multivariate analysis } \\
& P value & \multicolumn{1}{|c|}{ Hazard Ratio } \\
\hline Stage & $<10^{-16}$ & $2.34(1.64-3.35)$ \\
\hline Gender & 0.9737 & $0.99(0.61-1.6)$ \\
\hline Smoking history & 0.0296 & $0.55(0.32-0.94)$ \\
\hline $\begin{array}{l}\text { IHH mRNA } \\
\text { expression }\end{array}$ & 0.0297 & $0.61(0.39-0.95)$ \\
\hline
\end{tabular}

e

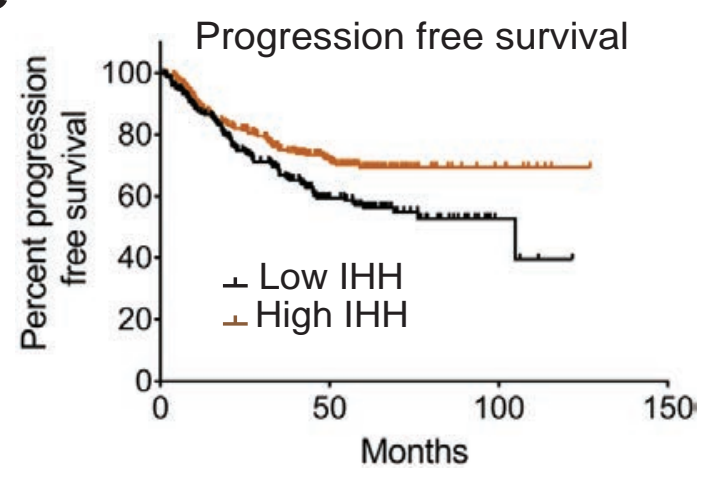

\section{f}

\begin{tabular}{|l||l|c|}
\hline \multicolumn{3}{|l|}{ Progression free survival multivariate analysis } \\
& P value & Hazard Ratio \\
\hline Stage & $<10^{-16}$ & $2.16(1.57-2.96)$ \\
\hline Gender & 0.5889 & $1.13(0.73-1.74)$ \\
\hline Smoking history & 0.8287 & $0.95(0.6-1.5)$ \\
\hline $\begin{array}{l}\text { IHH mRNA } \\
\text { expression }\end{array}$ & 0.0244 & $0.64(0.44-0.94)$ \\
\hline
\end{tabular}


Fig. 6 certified by peer review) is the author/funder. All rights reserved. No reuse allowed without permission.

a

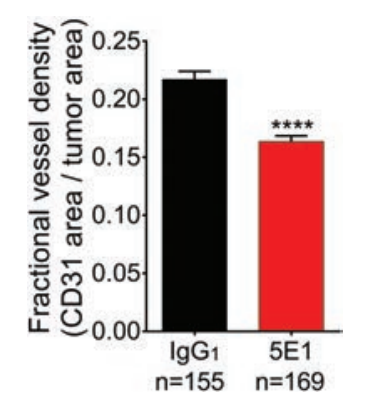

b

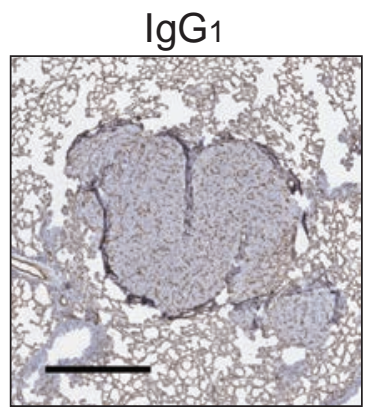

$\lg \mathrm{G}_{1}$

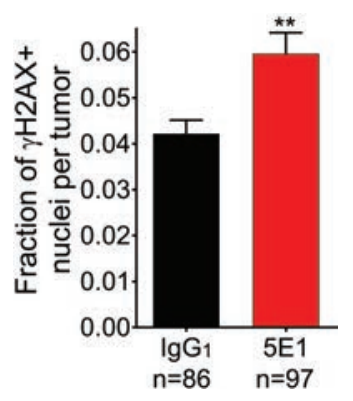

d

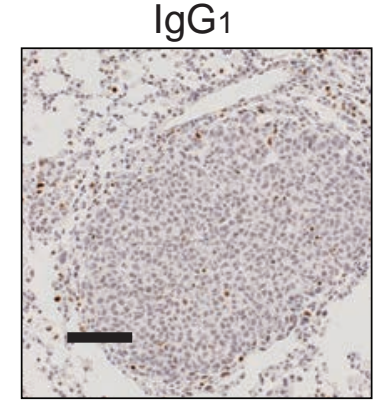

$5 \mathrm{E} 1$

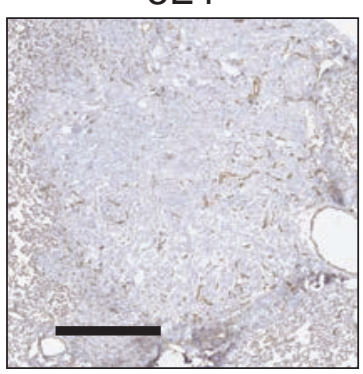

$5 \mathrm{E} 1$

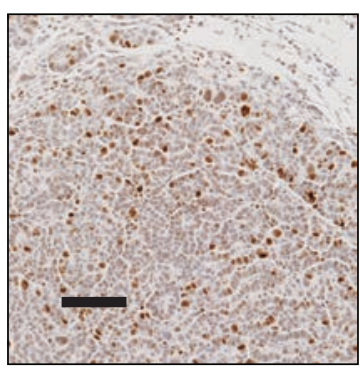

e
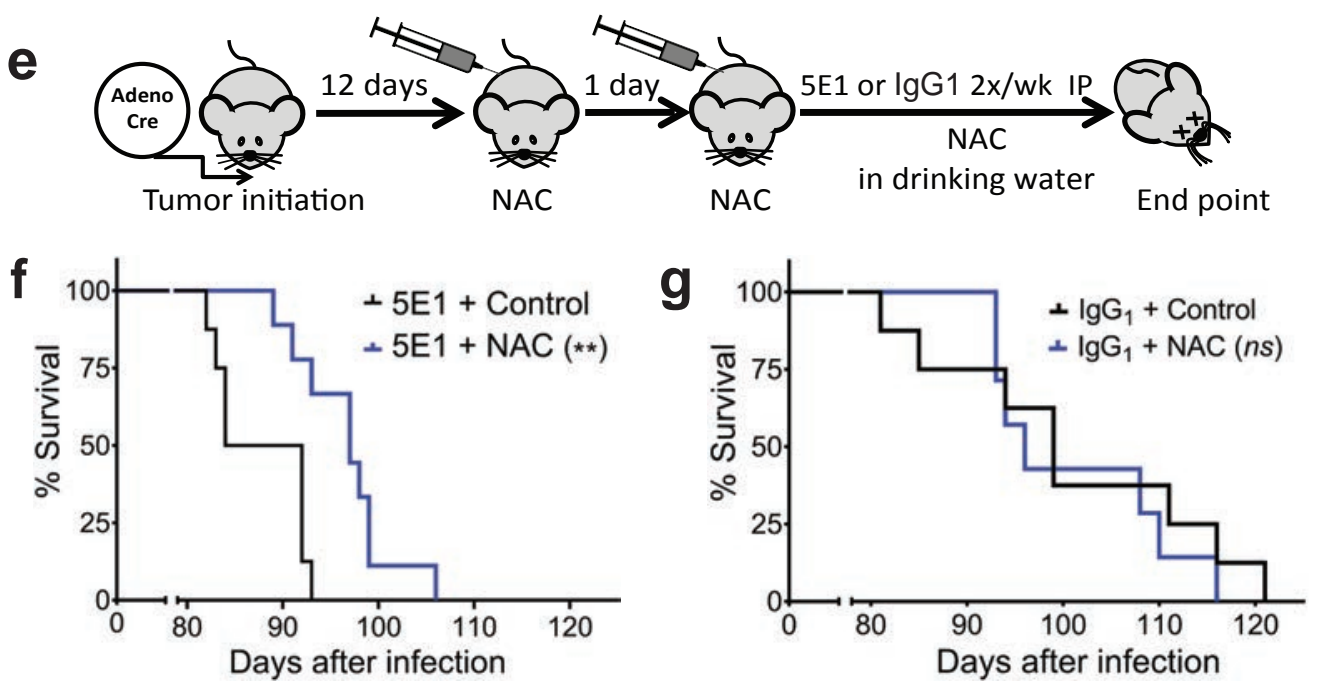

h
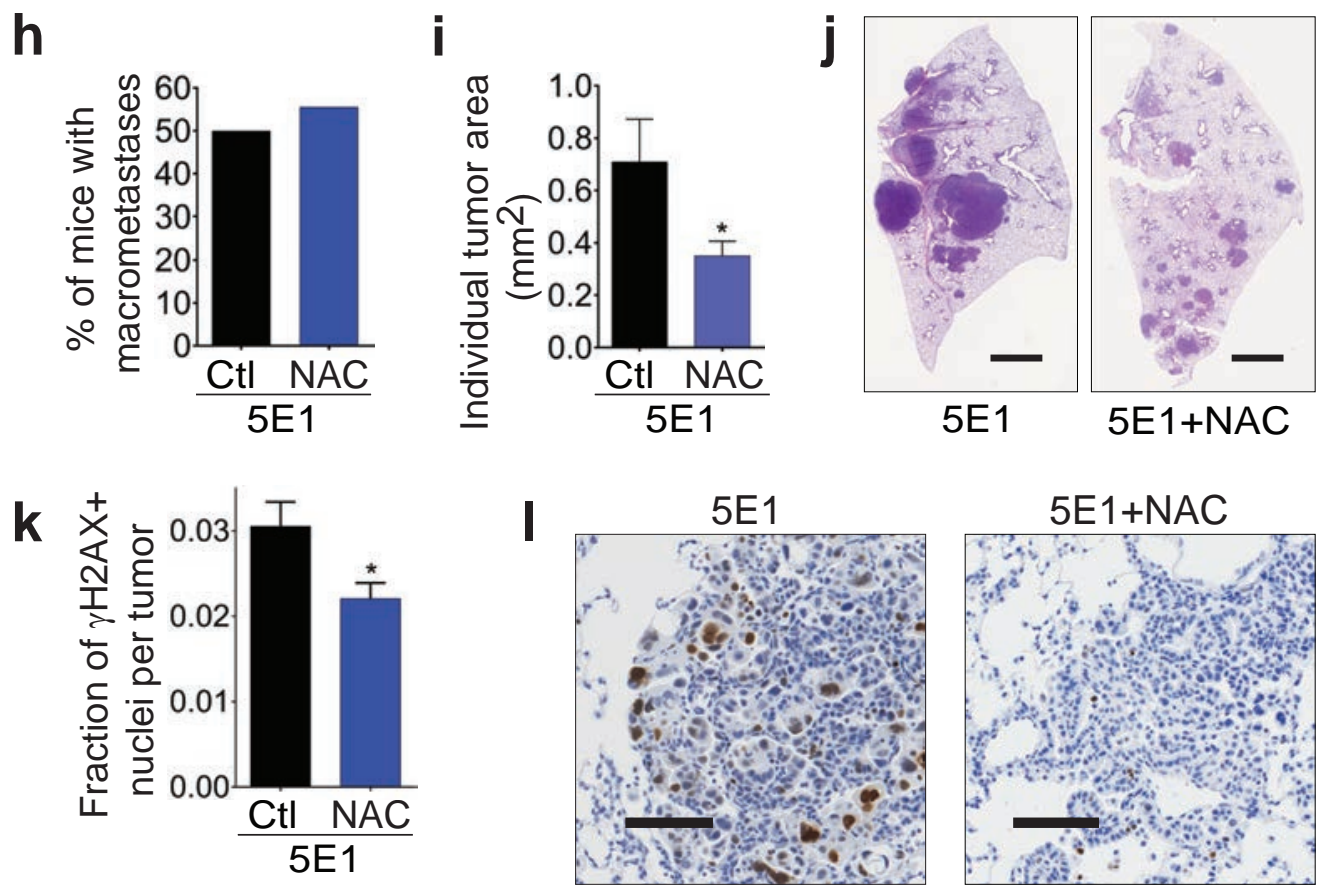